\title{
An Investigation of the Ship Safety Distance for Bridges across Waterways Based on Traffic Distribution
}

\author{
Woo-Ju Son ${ }^{1}\left(\mathbb{D}\right.$, Jeong-Seok Lee ${ }^{1}\left(\mathbb{D}\right.$, Hyeong-Tak Lee ${ }^{2}(\mathbb{D})$ and Ik-Soon Cho ${ }^{3, * \mathbb{D}}$ \\ 1 Graduate School, Korea Maritime \& Ocean University, Busan 49112, Korea; wooju@kmou.ac.kr (W.-J.S.); \\ shoesy548@kmou.ac.kr (J.-S.L.) \\ 2 Ocean Science and Technology School, Korea Maritime \& Ocean University, Busan 49112, Korea; \\ gudxkr518@kmou.ac.kr \\ 3 Division of Global Maritime Studies, Korea Maritime \& Ocean University, Busan 49112, Korea \\ * Correspondence: ischo@kmou.ac.kr; Tel.: +82-51-410-5072
}

Received: 8 April 2020; Accepted: 4 May 2020; Published: 8 May 2020

\begin{abstract}
For ship passage safety, a bridge across a waterway is a risk for accidents. However, no standard for the safe distance between a bridge and a ship is available in Korea. The UK MCA considers the $90 \%$ confidence interval of traffic distribution as the acceptable passage range, using it for measuring the separation between offshore wind farms. In this study, an optimal ship safety distance is proposed by evaluating traffic distribution at the Incheon and Busan harbor bridges and analyzing the confidence intervals. The results, based on the Z-score, reveal that at the Incheon bridge, all but one ship for 2-way departure were in circulation within the $95 \%$ confidence interval range, whereas at the Busan harbor bridge, six ships for arrival and two ships for departure were outside the $95 \%$ range. Based on the results of this study, the design of bridges across waterways can incorporate traffic distribution corresponding to each port.
\end{abstract}

Keywords: safety distance; traffic distribution; confidence interval; bridge across waterway; port characteristics

\section{Introduction}

Bridges across waterways are currently present in waters navigated by ships worldwide, including Korea, facilitating logistics transportation and improving road user convenience. These, however, constitute a risk factor for ships navigating below by increasing the probability for accidents. Serious collisions between ships and bridges are reported globally, and worldwide severe collisions between bridges and ships occur more than once a year [1]. With an annual average of 9.7 maritime accidents was related to bridges across waterways since the 1990s [2]. Park et al. [3] indicated that about $90 \%$ of maritime accidents associated with bridges across waterways occur at bridges with a primary span length of $\leq 500 \mathrm{~m}$.

Korea's maritime construction is driven by economic logic, without fully considering the safety of ships and the impact on the port's operation. In particular, for the Incheon bridge completed in 2009, social costs were incurred due to varying views on the main span length [4]. Lee et al. [5] surveyed 63 pilots and 46 captains and navigation officers on the physical distance between the bridge and the ship, with more than $85 \%$ indicating $\geq 3.0 \mathrm{~B}$, proposing a safety distance from the bridge pier of over 3.0 B from the fairway's end.

Subsequent research on bridges across waterways employed safety assessment methods and analysis of ship-handling simulations to improve the way ships traverse such bridges [6]. In fact, studies suggested that analysis of the construction procedures for bridges across waterways in Korea 
is crucial [7]; one study was carried out on the advancement of ship handling simulations for bridges across waterways [8]. However, no study exists to verify the suggested 3.0 B distance from between the bridge pier and the ship's passage by quantitative analysis for bridges across waterways. Therefore, adjustment of fairways and bridges across waterways were performed without considering the safety distance from the piers and the ship's route.

Le Guyader et al. [9] conducted density analysis and kernel density analysis on the $90 \%$ traffic distribution probability range in the bay of Brest, France. In selecting the distance between a ship and an offshore wind farm (Figure 1), the UK Maritime and Coastguard Agency (MCA) [10] considered a $90 \%$ confidence interval clearance range as acceptable.

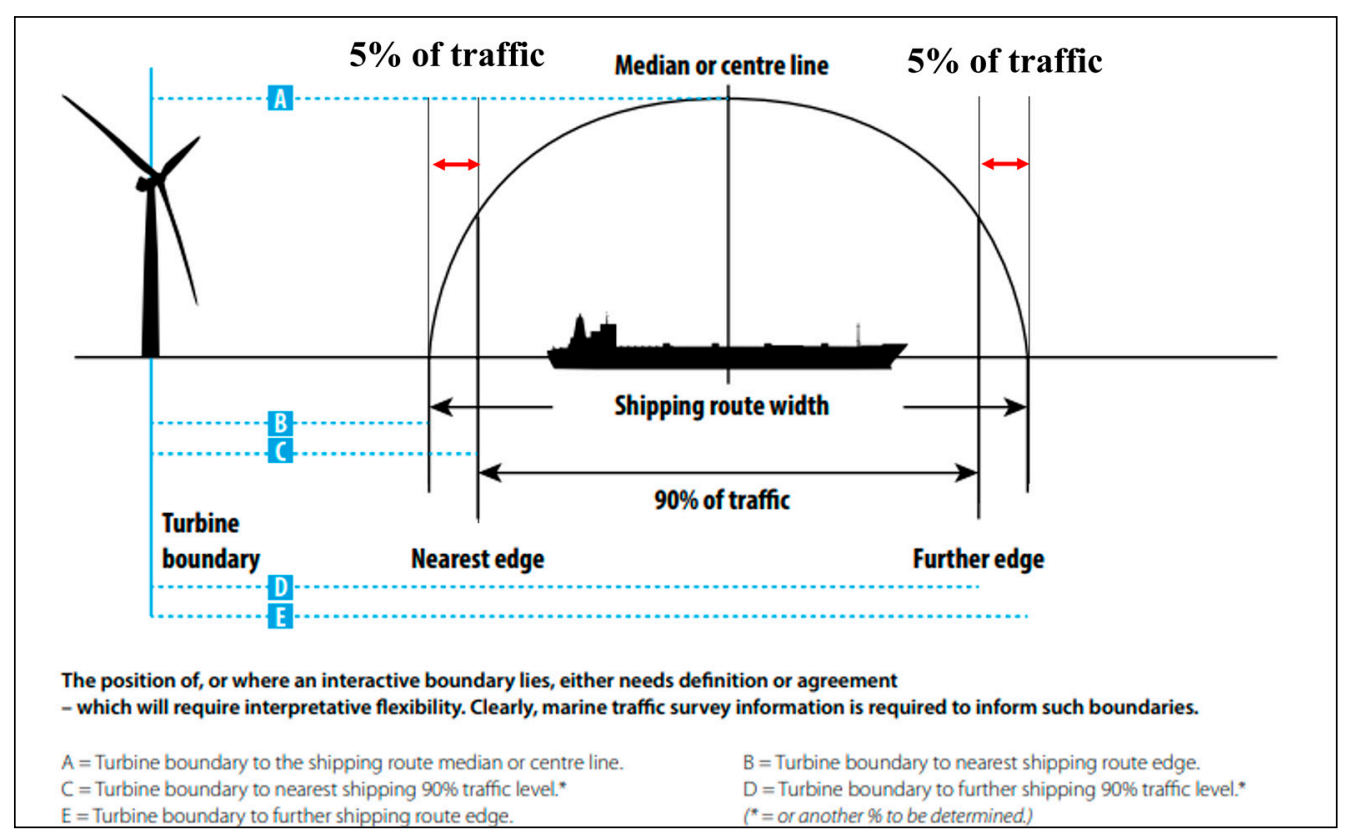

Figure 1. Safety distance between ship traffic and wind turbines recommended by the UK MCA.

In this study, we intend to propose a range of safety distances for ships by evaluating the traffic distributions around bridges across waterways. The maritime traffic pattern of a specific sea area is influenced by the shipping route characteristics and the surrounding topographical environment [11]. In this study, the target bridges are the Incheon bridge involving a symmetrical fairway and the Busan harbor bridge representing an asymmetrical fairway in Korea.

The maritime traffic survey utilizes data for at least 6-7 days, considering the weekly variation in traffic volume [12]. In addition, Automatic Identification System (AIS) data were collected for June 2019 to perform a more accurate distribution survey. In the port traffic distribution analysis, only merchant ships (Cargo, Tanker, and Passenger) were utilized for regular navigation. For the Incheon bridge, the total tonnage of ships shown in Table 1 is divided into 1-way and 2-way traffic [13]. Therefore, the data involve arrival and departure, with distances measured between the bridge pier and the nearest ship when traversing the bridge pier.

Table 1. Classification of the ships according to passage rules at the Incheon bridge.

\begin{tabular}{ccc}
\hline \multirow{2}{*}{ Classification } & \multicolumn{2}{c}{ Gross Tonnage } \\
\cline { 2 - 3 } & Cargo & Tanker, Passenger \\
\hline 2-way & $5 \mathrm{~K}<x<50 \mathrm{~K}$ & $1 \mathrm{~K}<x<50 \mathrm{~K}$ \\
1-way & & $50 \mathrm{~K}<x$ \\
\hline
\end{tabular}


Meanwhile, for the Busan harbor bridge, no passage rules already exist. Small ships that would encounter no problem at the passage were also excluded from the data to ensure the analysis reflected regular ships navigation. Although several ships classifying methods exist, the size classification based on 1000 GT was employed following the criteria (Table 2) for small ships defined in assessment on navigational stress and fairway' width according to traffic flow [14].

Table 2. Classification of ships by size according to precedent study.

\begin{tabular}{cccc}
\hline \multicolumn{2}{c}{ Classification } & LOA(m) & Standard Deviation \\
\cline { 1 - 2 } Size & Gross Tonnage & & \\
\hline Small & $0-1 \mathrm{~K}$ & 48 & \pm 20 \\
Medium & $1 \mathrm{~K}-10 \mathrm{~K}$ & 104 & \pm 20 \\
Large & Over $10 \mathrm{~K}$ & 240 & \pm 50 \\
\hline
\end{tabular}

Table 3 shows the handling of missing values through the data preprocessing. AIS data had missing values for $46(2.5 \%)$ of $1822(100.0 \%)$ ships. In the case of AIS data, it is a very important system that transmits the ship's own data and at the same time accepts information from other ships to help determine the surrounding situation. However, AIS errors due to the non-entry of AIS information by operators and radio transmission errors interfere with decision making [15]. In this study, 46 ships due to AIS error were completely eliminated by using list-wise deletion, one of the techniques for processing missing values. List-wise deletion affects the statistical power of the tests conducted [16]. Therefore, this study analyzed whether the preprocessed sample obtained sufficient sample power through statistical sample power analysis through $\mathrm{G}$ * power version 3.1.7.9.

Table 3. Result of missing values treatment according to data preprocessing.

\begin{tabular}{cccc}
\hline Bridge & Collected AIS Data & Missing Values & Target Values \\
\hline Incheon bridge & $982(100.0 \%)$ & $22(2.2 \%)$ & $960(97.8 \%)$ \\
\hline Busan harbor bridge & $840(100.0 \%)$ & $24(2.9 \%)$ & $816(97.1 \%)$ \\
\hline Total & $1822(100.0 \%)$ & $46(2.5 \%)$ & $1776(97.5 \%)$ \\
\hline
\end{tabular}

For GPS position errors that occur when analyzing historical tracks, the program MaTSAS (Marine Traffic Safety Assessment Solution) was used to remove outliers in two dimensions of the GPS position and smoothed the removed values through the average of the distances between the GPS positions. Additionally, in this study, GPS position, heading, speed over ground, Maritime Mobile Service Identity (MMSI), dimensions of the ship, type of cargo, and gross tonnage data were filtered out of numerous AIS raw data to analyze ship safety distance. For the filtered data, they were classified according to arrival and departure based on gross tonnage using aggregation, one of the data transformation techniques [17].

After compiling all results, the scope of the bridges across waterways and the confidence interval were analyzed to evaluate safety distances corresponding to the traffic distribution characteristics. $\mathrm{R}$ Studio version 3.6.3 was utilized for the traffic distribution analysis. An overview of the data preprocessing and processing methods and a flow chart of the methodology are displayed in Figures 2 and 3. 


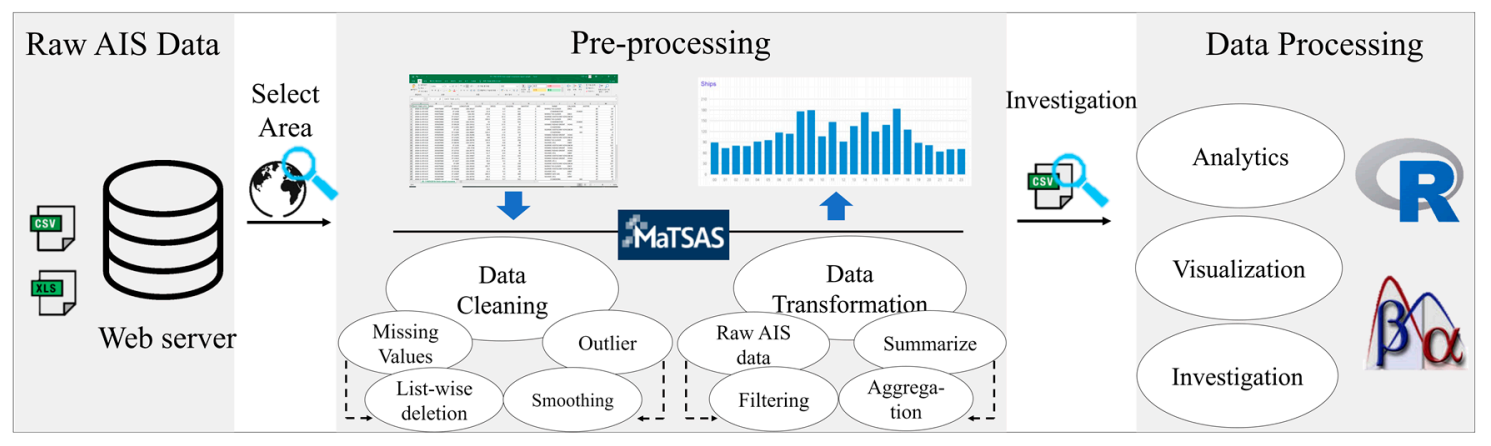

Figure 2. Overview of data preprocessing and processing method.

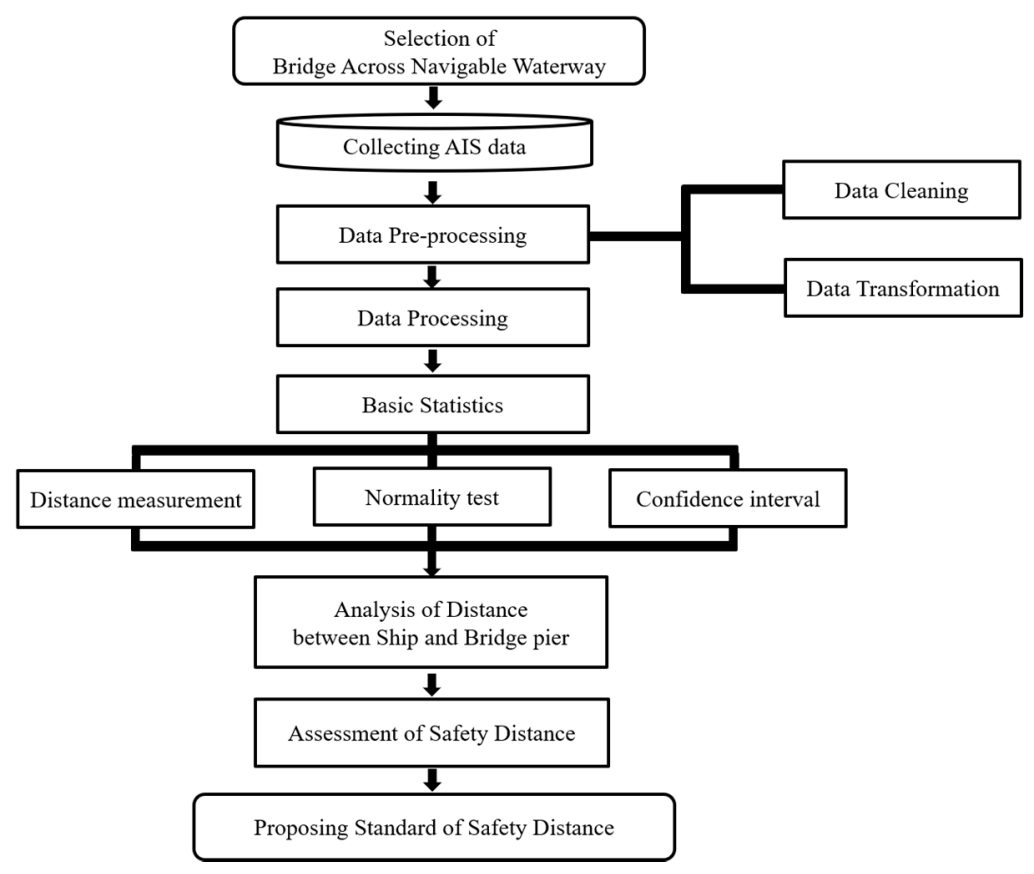

Figure 3. Flow chart used for investigating the safety distance between a ship and the bridge pier.

\section{Characteristics of the Target Port and Data Collection}

\subsection{Target Port}

Yu and Kim [18] considered the maritime traffic characteristics of Ulsan port to improve the collision probability assessment method for Korea Maritime Safety Audit. In the present study, to suggest the safety distance suitable for the traffic characteristics of each port, annual data analysis for 2015-2019 on the number of ships, arrival and departure volumes, and accidents was conducted to identify traffic characteristics of the Busan and Incheon ports in Korea. These are among Korea's leading trade ports, with high traffic volumes and shipment. Their locations in the Korean peninsula are depicted in Figure 4. With both, their ships' count trends are decreased from 2015 to 2019 , but Incheon's annual freight volumes are maintained, and in Busan, annual freight volumes are increasing. This means that the size of ship has increased every year (Table 4) [19]. 

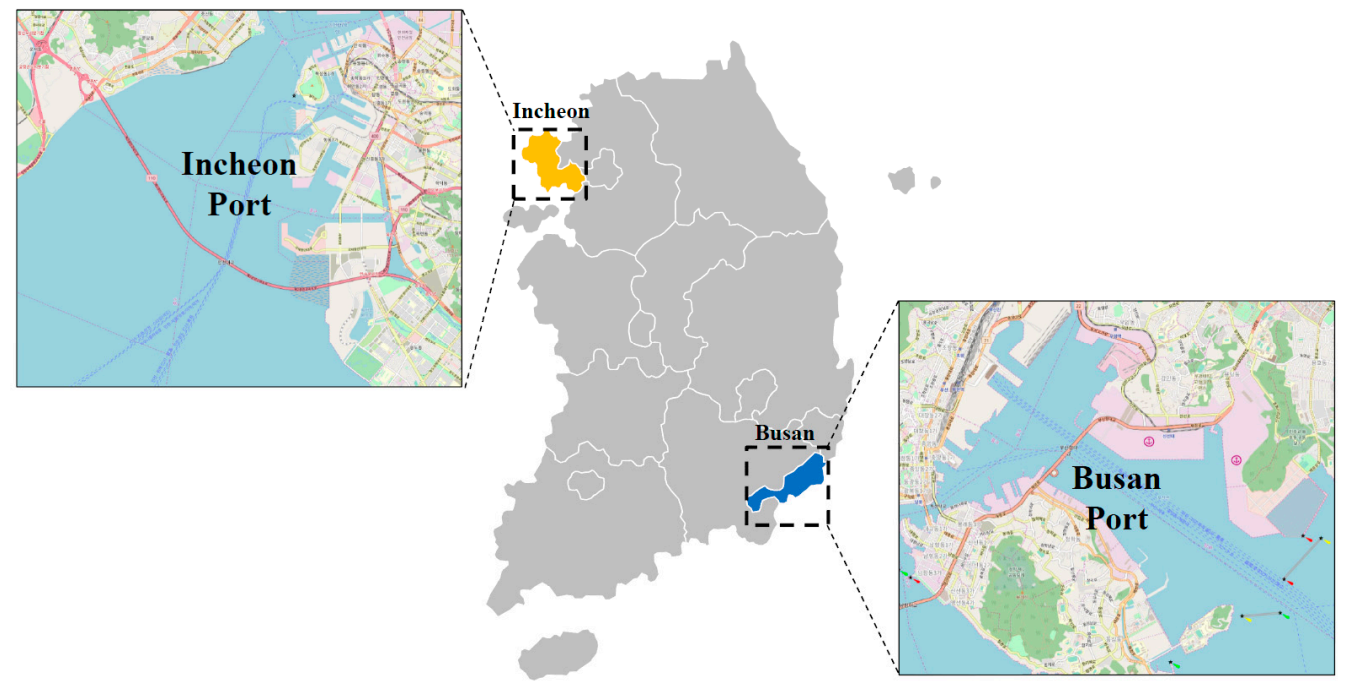

Figure 4. Geographical locations of the Busan and Incheon ports in the Korean peninsula.

Table 4. Port status from 2015-2019 by count and gross tonnage.

\begin{tabular}{ccccccc}
\hline \multirow{2}{*}{ Unit } & \multirow{2}{*}{ Port } & \multicolumn{5}{c}{ Annual Status } \\
\cline { 3 - 7 } & & $\mathbf{2 0 1 5}$ & $\mathbf{2 0 1 6}$ & $\mathbf{2 0 1 7}$ & $\mathbf{2 0 1 8}$ & $\mathbf{2 0 1 9}$ \\
\hline \multirow{2}{*}{ Count } & Incheon $^{*}$ & 37,560 & 37,407 & 36,215 & 31,351 & 29,753 \\
& Busan $^{1}$ & 98,087 & 100,197 & 99,687 & 94,816 & 93,701 \\
\hline \multirow{2}{*}{ G/T } & Incheon $^{*}$ & $378,218,349$ & $386,789,768$ & $391,694,597$ & $380,847,451$ & $361,696,734$ \\
& Busan $^{1}$ & $1,247,878,352$ & $1,324,573,420$ & $1,332,261,065$ & $1,345,183,479$ & $1,361,337,334$ \\
\hline
\end{tabular}

${ }^{1}$ For Busan, the statistics for the Busan port and Busan new port are combined.

The status of maritime accidents from 2015 to 2019 at the ports of Busan and Incheon are presented in Table 5, with annual averages of 56.2 and 34.6, respectively. Although only 18 accidents were reported at Busan port in 2018, marine accidents continued to occur until the date [20].

Table 5. Summary of marine accidents in the Incheon and Busan ports of Korea from 2015-2019.

\begin{tabular}{ccccccc}
\hline \multirow{2}{*}{ Unit } & \multirow{2}{*}{ Port } & \multicolumn{5}{c}{ Annual Status } \\
\cline { 3 - 7 } & & $\mathbf{2 0 1 5}$ & $\mathbf{2 0 1 6}$ & $\mathbf{2 0 1 7}$ & $\mathbf{2 0 1 8}$ & $\mathbf{2 0 1 9}$ \\
\hline \multirow{2}{*}{ Count } & Incheon & 22 & 37 & 22 & 43 & 49 \\
& Busan & 66 & 85 & 52 & 19 & 59 \\
\hline
\end{tabular}

\subsection{Automatic Identification System (AIS) Data}

Due to ship to ship communication limitations and the shipping industry's network size, studies involving big data analysis were scant due to lack of data accumulation [21]. Recently, due to the development of $\mathrm{V}$-sat and other devices, communication problems between ships were resolved, and significant data were collected. Operational data provided by navigation devices such as GPS, AIS, and ECDIS are valuable for forecasting, decision making, and preventing accidents in the ship and shipping industry [22]. Among these, analyzing traffic characteristics of ports using AIS data is the basic surveying process for the flow of ships in the target areas, and collecting and analyzing the data. This allows the prediction of effects of the arrangement of routes and facilities used by ships on safety, providing important basic data for conducting a quantitative assessment of the traffic volume.

Traffic characteristics analysis was performed on AIS data collected using the procedure in Lee et al. [23] with the program MaTSAS [24]. The distances between ships and marine structures were 
also measured through MaTSAS following the same method in Son et al. [25]. The number of ships used during the data collection periods and associated data are presented in Table 6.

Table 6. Data collection period and the number of ships used during data collection.

\begin{tabular}{ccccc}
\hline Date & Bridge & \multicolumn{2}{c}{ Status } & Number of Ships \\
\hline \multirow{4}{*}{ 1-30 June 2019 } & \multirow{2}{*}{ Incheonbridge } & 2-way & Arrival & 487 \\
& & Departure & 412 \\
& & 1-way & Arrival & 30 \\
& & & Departure & 31 \\
\cline { 2 - 5 } & \multirow{2}{*}{ Busan harbor bridge } & \multirow{2}{*}{ 2-way } & Arrival & 409 \\
& & & Departure & 407 \\
\hline
\end{tabular}

In Korea, Nationwide Differential Global Positioning System (NDGPS) is in operation, of which Maritime DGPS consists of 11 reference stations and 8 integrity monitoring stations. In the case of dynamic positioning, the accuracy was analyzed into $1.9 \mathrm{~m}$ in two dimensions at mean $25 \mathrm{~km} / \mathrm{h}$ (12.7 knots) [26]. The average sailing speeds passing through the target bridge are depicted in Table 7; Incheon bridge was analyzed to be 11.4 knots for arrival and 10.8 knots for departure, while the average speed of ships on the Busan Harbor bridge was analyzed to be 10.5 knots for arrival and 10.7 knots for departure. The GPS navigation accuracy in two dimensions in the target port area was analyzed to be less than $1.9 \mathrm{~m}$. Therefore, the GPS error was not considered because it was analyzed as an insignificant value compared to the distance under analysis.

Table 7. Sailing speeds passing through the target bridge.

\begin{tabular}{ccccc}
\hline \multirow{2}{*}{ Bridge } & \multicolumn{2}{c}{ Arrival } & \multicolumn{2}{c}{ Departure } \\
\cline { 2 - 5 } & Average (knots) & S.D (knots) & Average (knots) & S.D (knots) \\
\hline Incheon bridge & 11.4 & 2.0 & 10.8 & 2.5 \\
$\begin{array}{c}\text { Busan harbor } \\
\text { bridge }\end{array}$ & 10.5 & 3.6 & 10.7 & 3.1 \\
\hline
\end{tabular}

Dynamic data of Class-A AIS are received at every period of $10 \mathrm{~s}$ for vessels sailing below 14 knots. When changing course during vessels sailing below 14 knots, AIS data are received at every period of $3.3 \mathrm{~s}$ [27]. If the distance from the GPS position to the bridge pier is measured for the collected AIS data, an error may occur. Therefore, the nearest distance between the ship and the bridge pier was measured through a historical track, in which the GPS Position was connected by one line according to MMSI. However, there was a limitation in considering the Consistent Common Reference Point (CCRP) of all target ships. Therefore, it was assumed that the AIS receiver was installed on the ship's centerline.

The Incheon bridge is the largest in Korea, with a main span of $800 \mathrm{~m}$, and several ships pass through the side of the bridge pier and through the main bridge piers. The ships navigating the main span are primarily merchant ships, while those utilizing the sides are fishing boats and others qualify as low passenger vessels (Figure 5a). The Busan port's eastern side involves a larger berthing capacity than the western side [28], with the port redevelopment project suggesting transforming the western side (1-4 pier) into a downtown facility [29]. The eastern is practically the principal hub for cargo transportation. Due to these characteristics, the Busan harbor bridge's fairway is the asymmetrical distance from the eastern pier based on the bridge across the waterway (Figure 5b). 


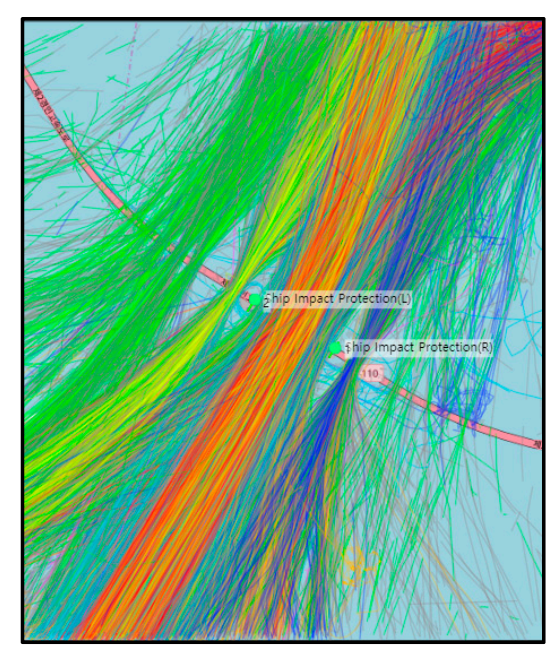

(a)
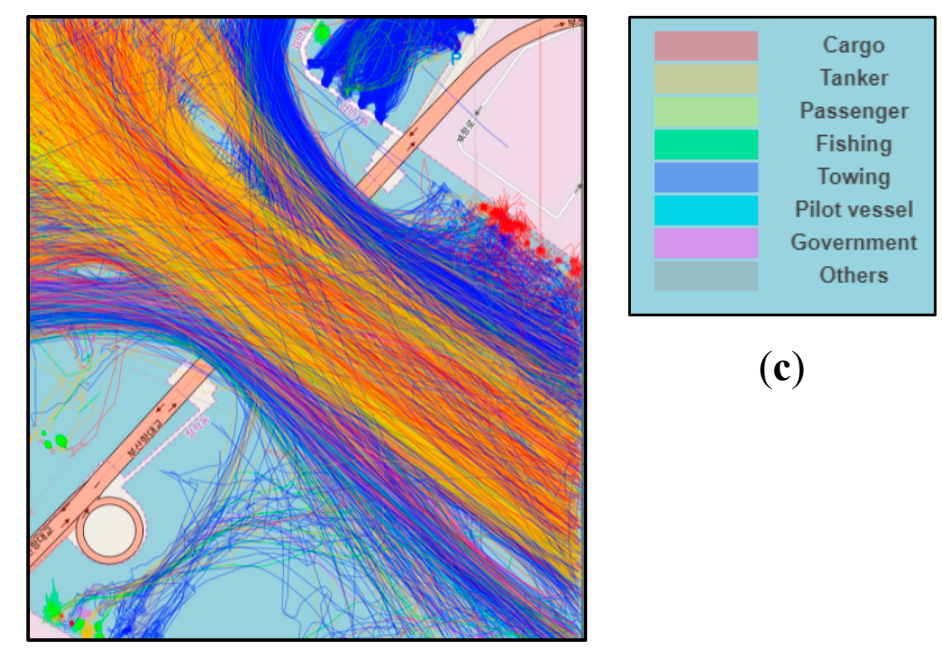

(c)

Figure 5. Historical tracks for the (a) Incheon bridge, (b) Busan harbor bridge and (c) legend.

The cable-stayed bridge reflecting previous research and design reports of the Incheon and Busan ports bridges is displayed in Figures 6 and 7. The ship impact protection ball at the Incheon bridge is the dolphin type [30], while that at the Busan harbor bridge is the artificial island type [31]. For the Incheon bridge, the layout of the fairway and navigable waterway below the bridge is nearly symmetric, whereas for the Busan harbor bridge, the fairway, and navigable waterway below bridge layout is asymmetrical.
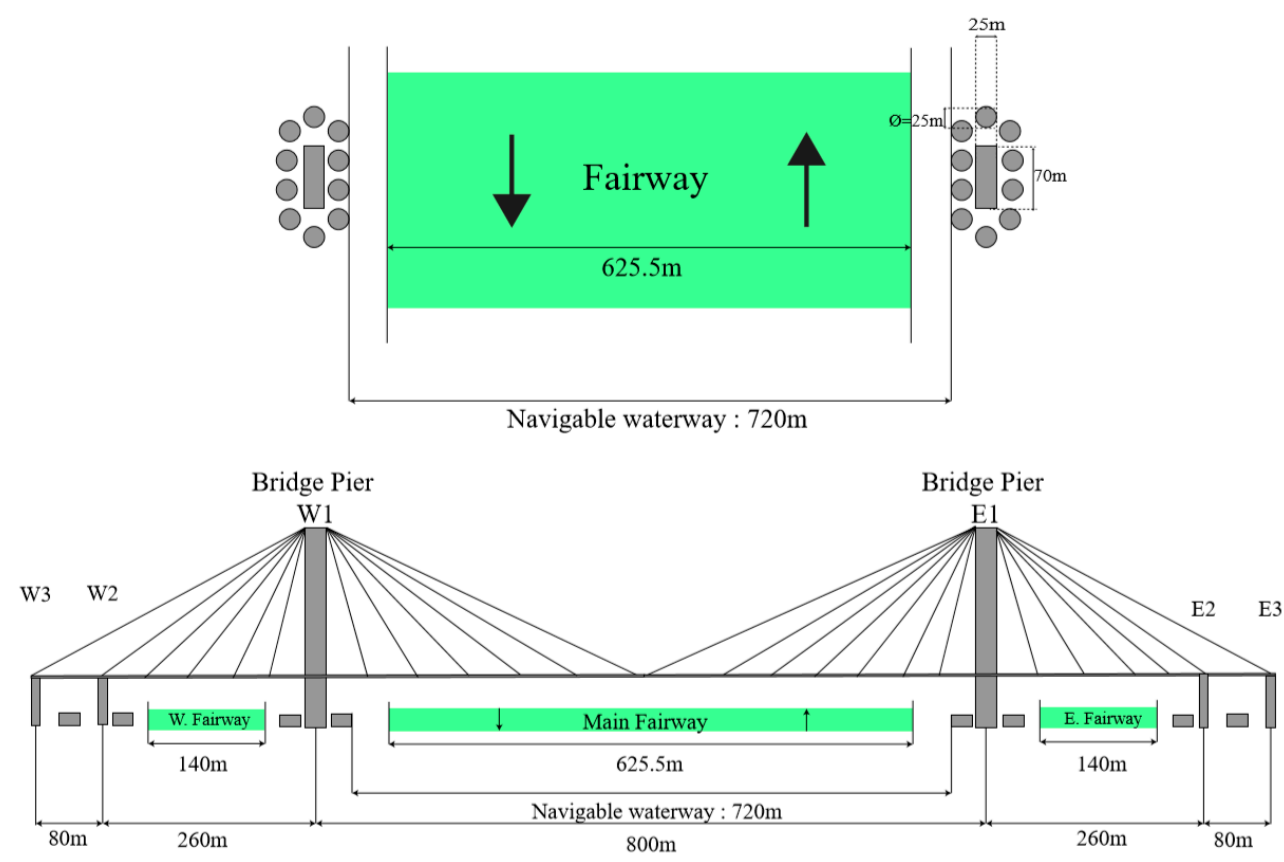

Figure 6. Cable-stayed part of Incheon bridge. 


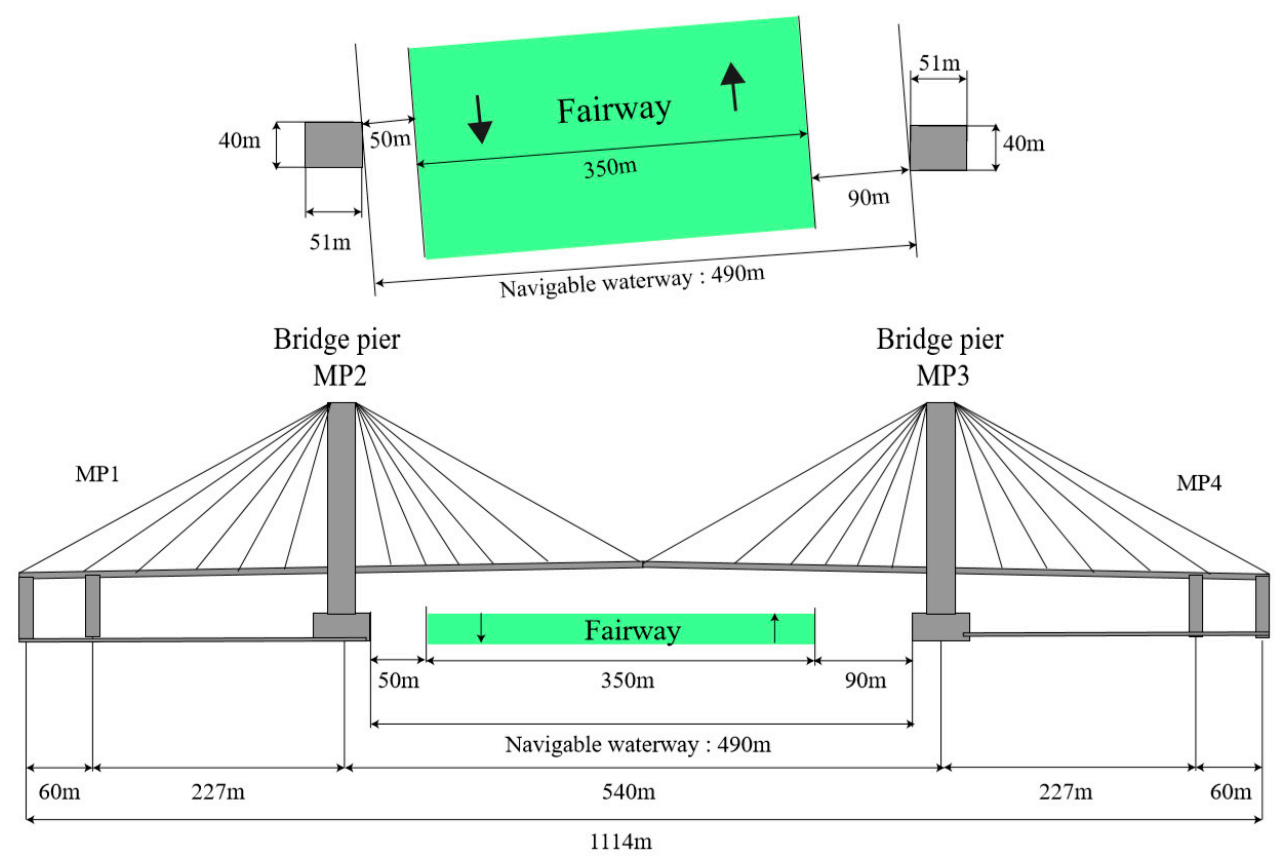

Figure 7. Cable-stayed part of Busan harbor bridge.

\section{Traffic Distribution Characteristics}

\subsection{Statistical Power Analysis}

In this study, traffic distribution characteristics were analyzed for comparison, considering differences in the layout of the fairway and the bridge across the waterway, which were designed according to the ports. Before comparison the traffic distribution characteristics, a sample size statistical power analysis was performed according to the effect size to assess whether the acquired data involve sufficient statistical verification capabilities. The effect size refers to the degree of association between two means divided by the standard deviation of the data, indicating the extent of a phenomenon in a population. This is also termed as Cohen's $\mathrm{d}$ and is expressed in following equation as:

$$
\operatorname{Effect} \operatorname{size}(\text { Cohen's } \mathrm{d})=\frac{\mu_{0}-\mu_{1}}{\sigma},
$$

where $\mu_{0}$ represents the mean of the distribution, $\mu_{1}$ is the mean of the null hypothesis, and $\sigma$ denotes the standard deviation of the distribution. Cohen [32] suggested that by using Type I $(\alpha)$ and Type II ( $\beta$ ) errors, the statistical verification of a sample is achieved when the Type I $(\alpha)$ is at 0.05 , and power $(1-\beta)$ is at 0.8 . The Type I error $(\alpha)$ refers to the probability of rejecting the true null hypothesis ( $p$-value), while the Type II error $(\beta)$ is that of not rejecting the false null hypothesis [33].

The AASHTO LRFD [34] assumes a normal routing distribution in calculating the geometric probability of collision, which is used to compute the bridge's annual crash frequency and model the mean value of that distribution as the centerline of the ship's transit path. In the statistical program $G^{*}$ power 3.1.9.7, $\alpha$ was set to 0.05 and (1- $\left.\beta\right)$ to 0.8 . The average of the null hypothesis was set as the centerline of the route's width, and the sample size was calculated through the one-sample $t$-test. The results are displayed in Table 8, with a sufficient sample size of the number of samples collected in this study analyzed. 
Table 8. Sample size verification by sample power calculation (one-sample $t$-test).

\begin{tabular}{cccccc}
\hline Bridge & \multicolumn{2}{c}{ Status } & Number of Ships & Effect Size & Sample Size \\
\hline \multirow{3}{*}{ Incheon bridge } & \multirow{2}{*}{ 2-way } & Arrival & 487 & 0.47 & 39 \\
& & Departure & 412 & 0.67 & 20 \\
\cline { 2 - 6 } & \multirow{2}{*}{ 1-way } & Arrival & 30 & 0.55 & 28 \\
& \multirow{2}{*}{ 2-way } & Departure & 31 & 0.89 & 12 \\
\hline \multirow{2}{*}{ Busan harbor bridge } & Arrival & 409 & 0.68 & 19 \\
& & Departure & 407 & 1.93 & 5 \\
\hline
\end{tabular}

\subsection{Normality Test}

Many studies have been conducted on the traffic distribution and patterns in a port because these are important for understanding and analyzing the flow of ships. Inoue [35] demonstrated that the traffic distribution for 1-way or 2-way traffic is a normal distribution. Kim and Kwon [36] assumed a normal distribution in analyzing the collision probability of the Mokpo bridge and Incheon bridge. Nguyen et al. [37] also evaluated the distribution of ships in the target waters as a normal distribution in developing the AIS preprocess program.

A ship can pass from the fairway's center to the right of the ship's bow direction. Considering these characteristics, the distance between the ship and bridge pier on the right side of the ship's bow side was measured and a normality test was conducted [35].

Many statistical techniques are available for the normality test. In a completely normal distribution, the skewness is 0 , and the kurtosis is 3 . The skewness measures the symmetry of the distribution, with negative $(-)$ values representing left-skewed and positive $(+)$ values right-skewed. Kurtosis is the degree of sharpness in the distribution, with $(+)$ values indicating the center is higher than normal and sharp, while ( - ) values highlight a flat distribution. For kurtosis, zero is used to facilitate analysis, and termed excess kurtosis [38]. The equations for skewness and excess kurtosis are expressed as follows:

$$
\begin{aligned}
\text { Skewness } & =\frac{\sum\left(x_{i}-\bar{x}\right)^{3}}{\left\{\sum\left(x_{i}-\bar{x}\right)^{2}\right\}^{\frac{3}{2}}}, \\
\text { Ex. Kurtosis } & =\frac{\sum\left(x_{i}-\bar{x}\right)^{4}}{\left\{\sum\left(x_{i}-\bar{x}\right)^{2}\right\}^{2}}-3,
\end{aligned}
$$

where $x_{i}$ represents the value of the $i$-th sample and $\bar{x}$ is the mean of the sample. Kline [39] proposed that when skewness and kurtosis are 0 in a standard normal distribution, if the distribution of the absolute value of the skewness variable is less than 3 and the absolute value of kurtosis does not exceed 10 , the distribution exhibits normality. The normality tests were performed through the skewness and kurtosis of the distributions as well as the Kolmogorov-Smirnov (K-S) test [40] and Normal Q-Q plot [41], which are commonly used for the normality test. Because of the normality test, the K-S test satisfied the normality in all cases except the 2-way traffic at the Incheon bridge. Due to the review of normality through skewness and kurtosis, both satisfied the conditions of normal distribution (Table 9). Normal Q-Q plot analysis shows that in most cases, the expected value displays a linear similarity to the Q-Q line, except for slight differences in the 150-250 m section of the Incheon bridge's 2-way traffic (Figures 8-10). 
Table 9. Summarized data for normality tests of traffic distributions.

\begin{tabular}{|c|c|c|c|c|c|c|}
\hline \multirow{3}{*}{ Classification } & \multicolumn{4}{|c|}{ Incheon Bridge } & \multirow{2}{*}{\multicolumn{2}{|c|}{$\begin{array}{c}\text { Busan Harbor Bridge } \\
\text { 2-Way }\end{array}$}} \\
\hline & \multicolumn{2}{|c|}{ 2-Way } & \multicolumn{2}{|c|}{ 1-Way } & & \\
\hline & Arrival & Departure & Arrival & Departure & Arrival & Departure \\
\hline Target (Centerline) & E1 & W1 & E1 & W1 & MP3 & MP2 \\
\hline Count & 487 & 412 & 30 & 31 & 409 & 407 \\
\hline $\operatorname{Max}(\mathrm{m})$ & 700 & 642 & 574 & 586 & 379 & 453 \\
\hline $\operatorname{Min}(\mathrm{m})$ & 163 & 116 & 234 & 228 & 126 & 216 \\
\hline Mean (m) & 350 & 337 & 359 & 335 & 245 & 197 \\
\hline S.D (m) & 107 & 94 & 75 & 73 & 36 & 38 \\
\hline Skewness & 0.66 & 0.98 & 0.69 & 1.39 & 0.44 & 0.41 \\
\hline Ex. Kurtosis & -0.39 & 3.62 & 0.44 & 5.92 & 0.88 & 3.13 \\
\hline K-S test (p-v) & $8.90 \times 10^{-5}$ & $3.10 \times 10^{-6}$ & 0.99 & 0.30 & 0.10 & 0.14 \\
\hline
\end{tabular}

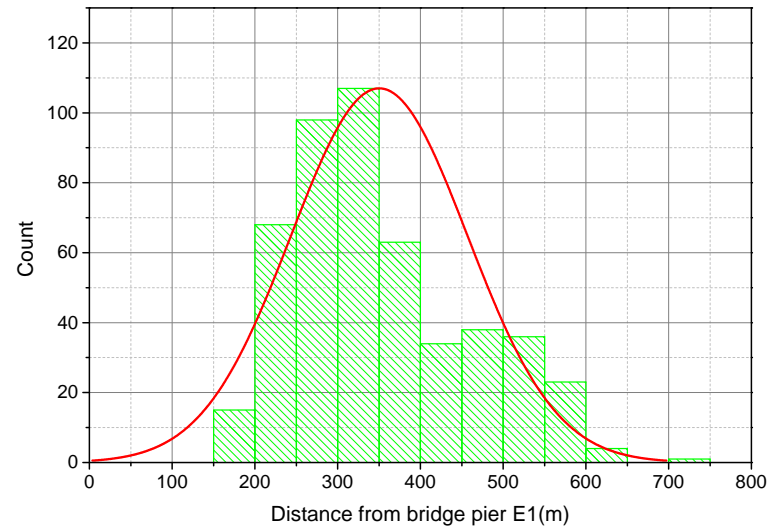

(a)

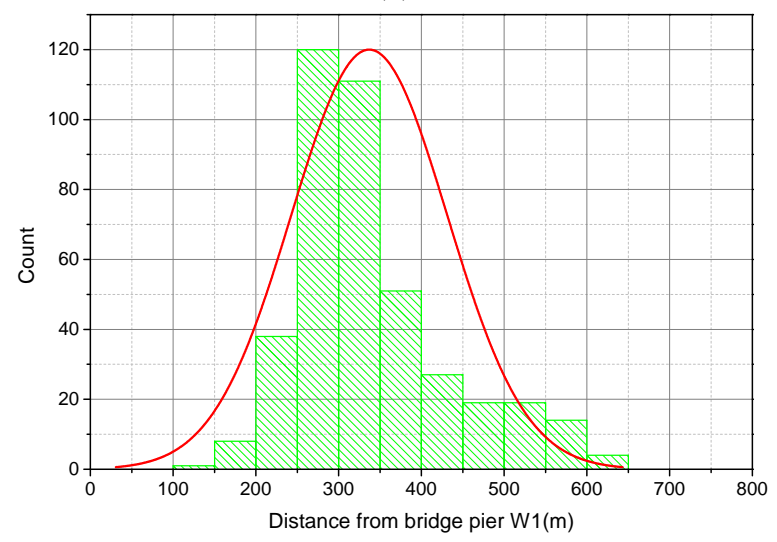

(c)

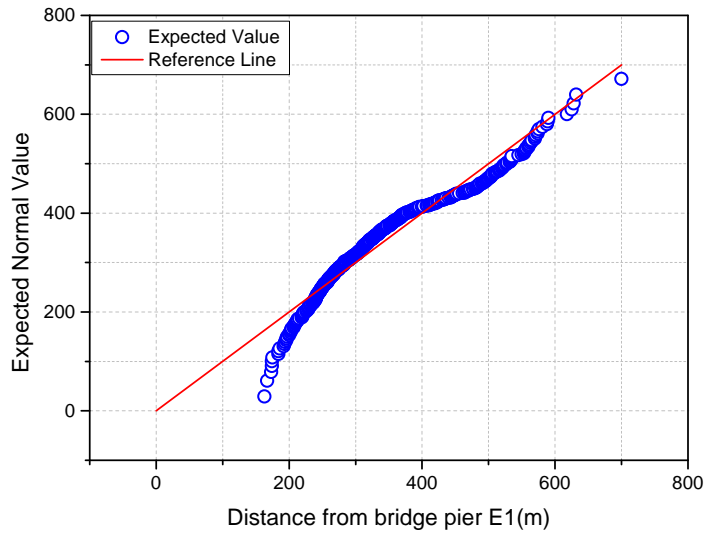

(b)

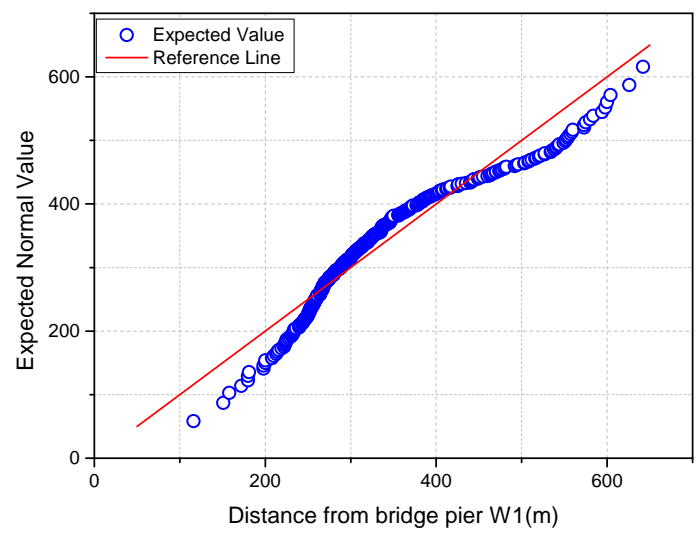

(d)

Figure 8. Histogram and Normal $Q-Q$ plots for the Incheon bridge data for $(\mathbf{a}, \mathbf{b}) 2$-way arrival and (c,d) 2-way departure. 


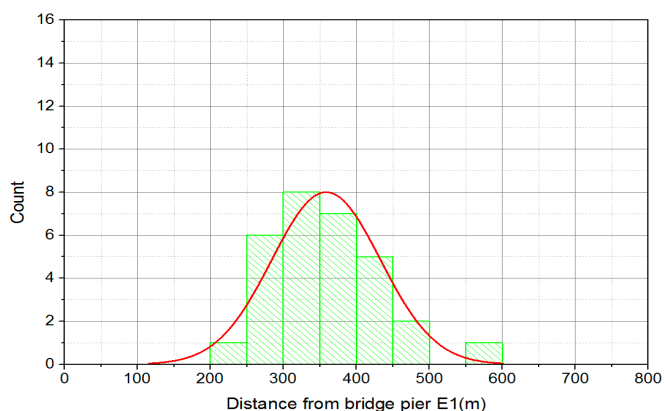

(a)

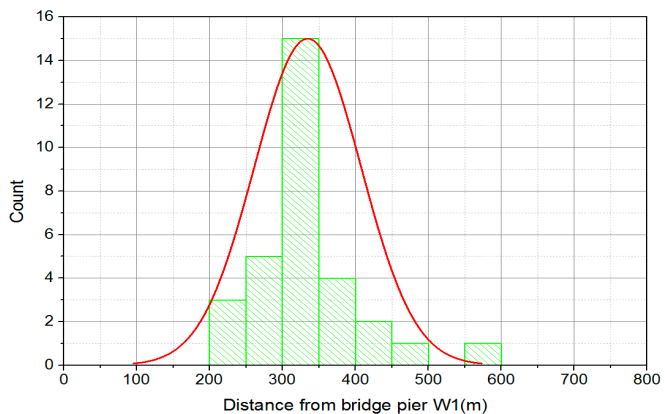

(c)

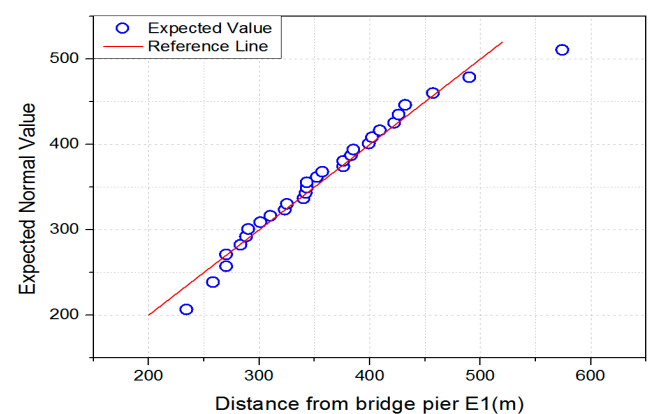

(b)

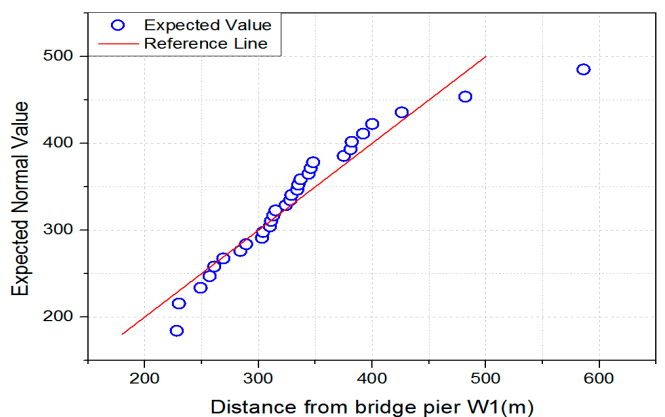

(d)

Figure 9. Histogram and Normal Q-Q plots for the Incheon bridge data for $(\mathbf{a}, \mathbf{b})$ 1-way arrival, and (c,d) 1-way departure.

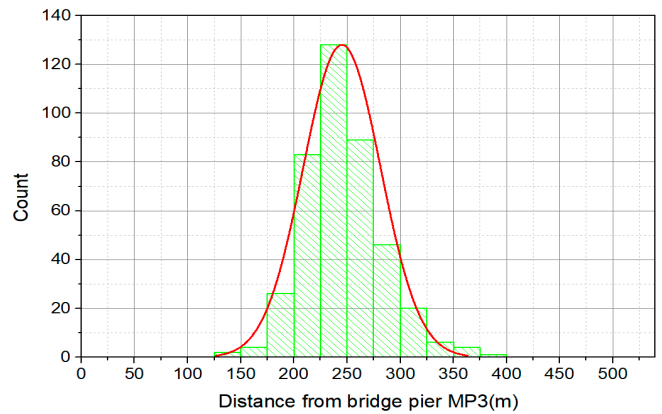

(a)

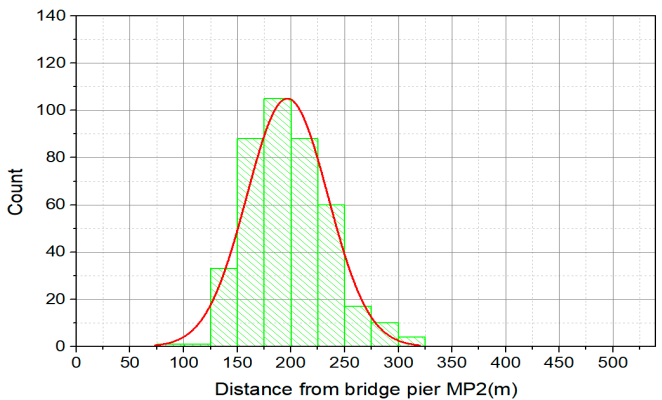

(c)

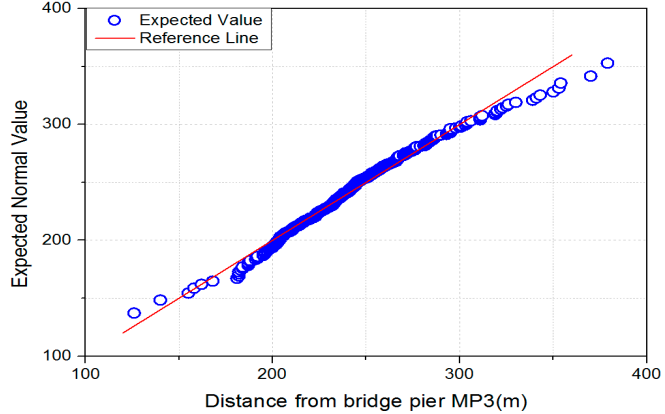

(b)

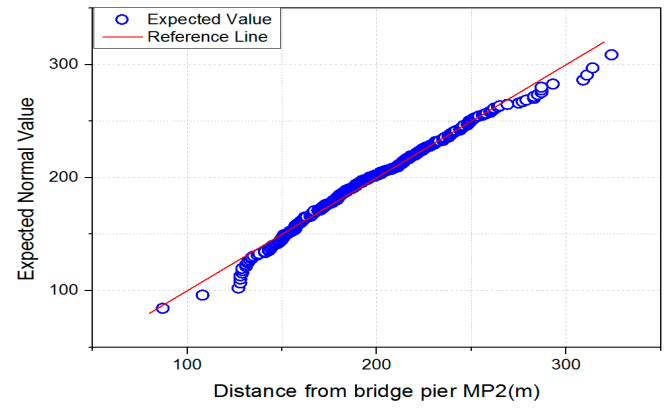

(d)

Figure 10. Histogram and Normal Q-Q plots for the Busan harbor bridge data for $(\mathbf{a}, \mathbf{b})$ arrival and (c,d) departure. 


\section{Ship Safety Distance}

\subsection{Analysis of Distance According to the Confidence Interval}

Based on the normality test on traffic distribution through the bridge pier, normal distribution is revealed except for the 2-way traffic at the Incheon bridge, with an approximate normal distribution. We assumed that the number of samples collected sufficiently represents statistical verification, and therefore, all traffic falls within a normal distribution.

The distance measurement method considering the width of the bridge pier, ship impact protection size, and ship breadth is shown in Figure 11. The distance corresponding to $C$ is within $80-99 \%$ of the confidence interval using the Z-score, which involves analyzing deviations and cumulative percentages through the mean and standard deviation in the normal distribution.

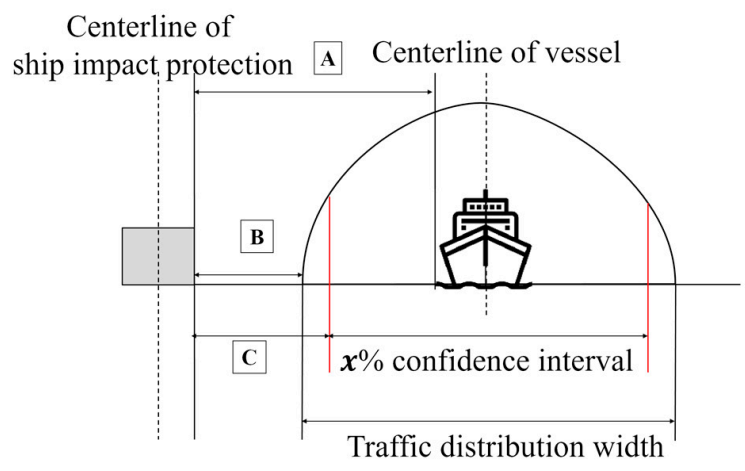

\section{A : Distance from ship impact protection to the ship's nearest edge \\ B : Distance from ship impact protection to nearest edge of distribution \\ C : Distance from ship impact protection to nearest edge of $x \%$ confidence interval}

Figure 11. Method used for analyzing the ship safety distance.

The distance corresponding to $\mathrm{C}$ is calculated from the following equation as:

$$
C=\mu-Z \sigma
$$

where $\mu$ is the mean of the traffic distribution considering the width of bridge pier, ship impact protection size, and ship breadth, $\mathrm{Z}$ represents the $\mathrm{Z}$-score value according to the confidence interval, and $\sigma$ denotes the standard deviation of the distribution. The distances between ships and bridge piers are presented in Table 10. These distances also consider the width of the bridge pier, ship impact protection size, and ship breadth.

Based on previous studies on the distribution of AIS data in the Bay of Brest [9] and the criteria for selecting the distance between an offshore wind farm and a ship clearance by the UK MCA [10], in this study, the distances between bridge piers and ships were calculated for analysis according to a confidence interval of $90-99 \%$. Data for ships that navigated outside the range of distances depending on the $90-99 \%$ confidence interval are presented in Table 11. For the Incheon bridge, $99 \%$ of the ships passed within the confidence interval, but the confidence interval extends beyond its fairway. Regarding the $95 \%$ confidence interval, one ship navigated outside the range for the 2-way departure traffic, accounting for $0.2 \%$ of the total 2-way departure traffic. At $90 \%$ confidence interval, 1-way departure traffic accounted for $6.5 \%$ of the entire Incheon bridge 1-way departure ships traffic, with three ships sailing outside the range for the 2-way departure traffic (Figures 12 and 13). At the Busan harbor bridge, two arrivals and one departure were analyzed, and the $99 \%$ confidence interval is within the fairway. At the $95 \%$ level, 6 arrivals and 2 departure ships were analyzed, while at $90 \%$, 13 arrivals and 16 departure ships were involved (Figure 14). 
Table 10. Summarized data of distances from ship to bridge pier based on the confidence interval.

\begin{tabular}{|c|c|c|c|c|c|c|c|}
\hline \multirow{3}{*}{\multicolumn{2}{|c|}{ Classification }} & \multicolumn{4}{|c|}{ Incheon Bridge } & \multirow{2}{*}{\multicolumn{2}{|c|}{$\begin{array}{c}\text { Busan Harbor Bridge } \\
\text { 2-Way }\end{array}$}} \\
\hline & & \multicolumn{2}{|c|}{ 2-Way } & \multicolumn{2}{|c|}{ 1-Way } & & \\
\hline & & Arrival & Departure & Arrival & Departure & Arrival & Departure \\
\hline Targ & edge) & E1 & W1 & E1 & W1 & MP3 & MP2 \\
\hline & & 487 & 412 & 30 & 31 & 409 & 407 \\
\hline & (m) & 299 & 286 & 300 & 276 & 220 & 171 \\
\hline & & 107 & 94 & 75 & 73 & 36 & 38 \\
\hline \multirow{5}{*}{$C(m)$} & $80 \% \mathrm{CI}$ & 162 & 165 & 205 & 180 & 173 & 123 \\
\hline & $85 \% \mathrm{CI}$ & 146 & 150 & 194 & 168 & 168 & 117 \\
\hline & $90 \% \mathrm{CI}$ & 124 & 131 & 179 & 153 & 160 & 109 \\
\hline & $95 \% \mathrm{CI}$ & 90 & 101 & 156 & 129 & 149 & 97 \\
\hline & $99 \% \mathrm{CI}$ & 25 & 44 & 111 & 84 & 127 & 74 \\
\hline
\end{tabular}

Table 11. Statistics for ships passing outside the confidence interval (90 to $99 \%$ ).

\begin{tabular}{ccccccc}
\hline \multirow{2}{*}{ Classification } & \multicolumn{3}{c}{ Incheon Bridge } & \multicolumn{2}{c}{ Busan Harbor Bridge } \\
\cline { 2 - 7 } & \multicolumn{2}{c}{ 2-Way } & \multicolumn{2}{c}{ 1-Way } & \multicolumn{2}{c}{ 2-Way } \\
\cline { 2 - 7 } & Arrival & Departure & Arrival & Departure & Arrival & Departure \\
\hline Count & $487(100 \%)$ & $412(100 \%)$ & $30(100 \%)$ & $31(100 \%)$ & $409(100 \%)$ & $407(100 \%)$ \\
\hline $\mathbf{9 0} \%$ CI & $2(0.5 \%)$ & $3(0.7 \%)$ & $1(3.3 \%)$ & $2(6.5 \%)$ & $13(3.2 \%)$ & $16(3.9 \%)$ \\
\hline $\mathbf{9 5 \%}$ CI & $0(0.0 \%)$ & $1(0.2 \%)$ & $0(0.0 \%)$ & $0(0.0 \%)$ & $6(1.5 \%)$ & $2(0.5 \%)$ \\
\hline $\mathbf{9 9} \%$ CI & $0(0.0 \%)$ & $0(0.0 \%)$ & $0(0.0 \%)$ & $0(0.0 \%)$ & $2(0.5 \%)$ & $1(0.2 \%)$ \\
\hline
\end{tabular}

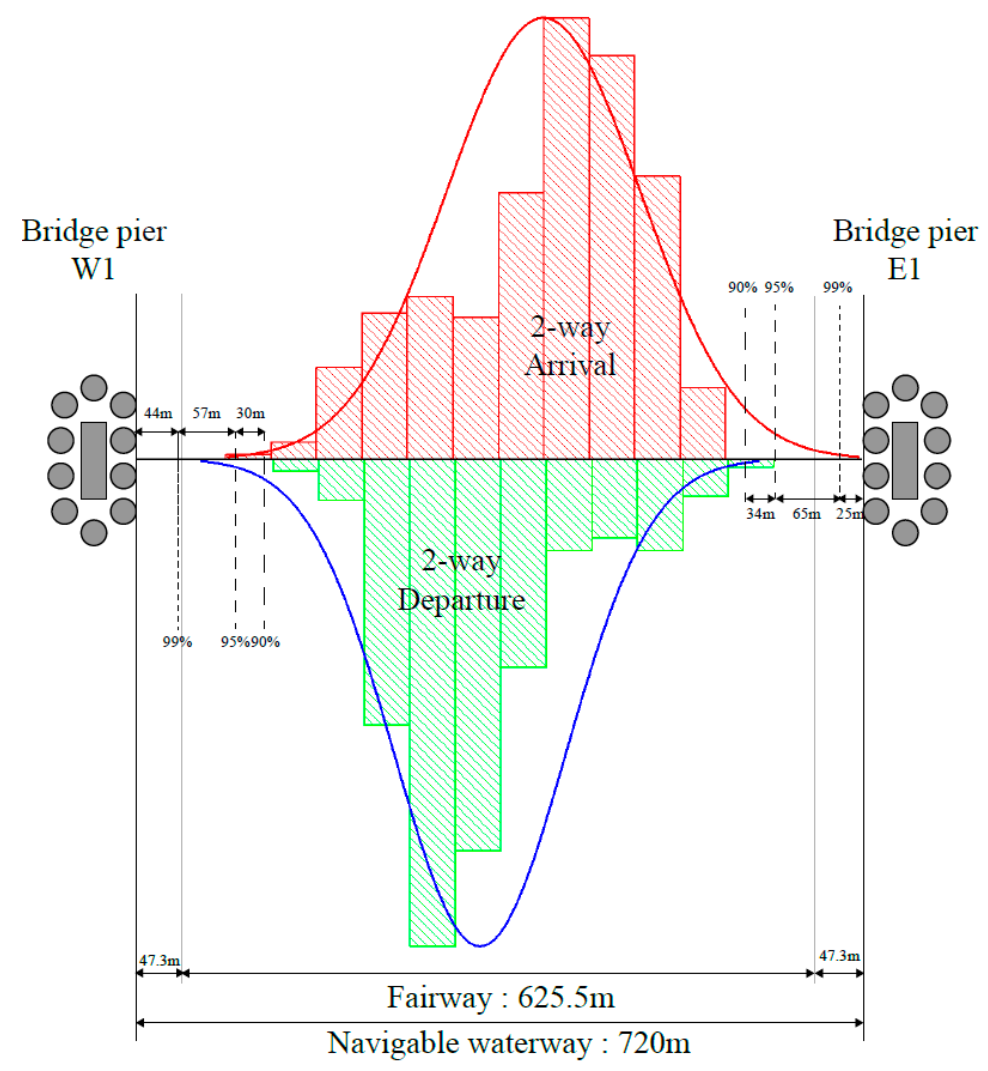

Figure 12. Traffic distribution at the Incheon bridge for 2-way traffic. 


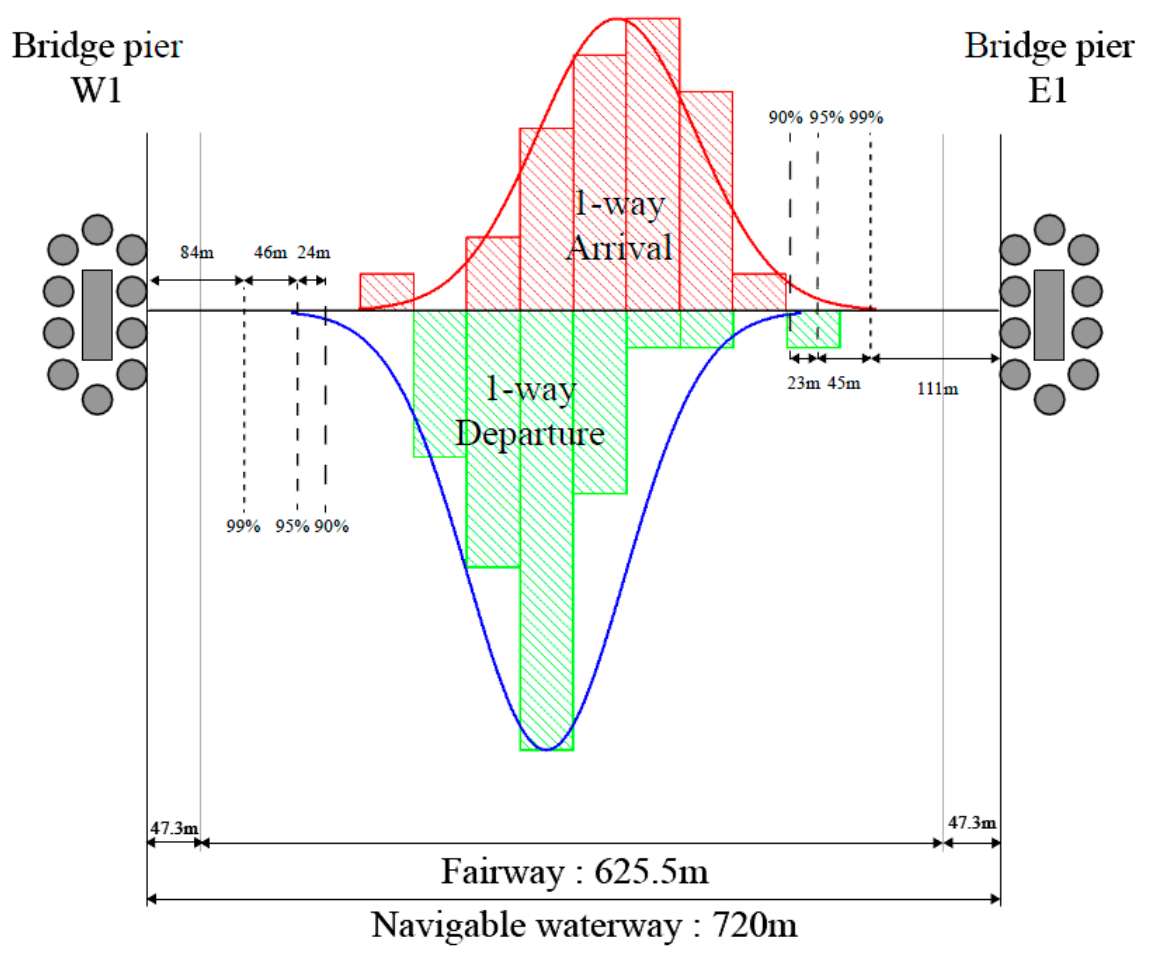

Figure 13. Traffic distribution at the Incheon bridge for 1-way traffic.

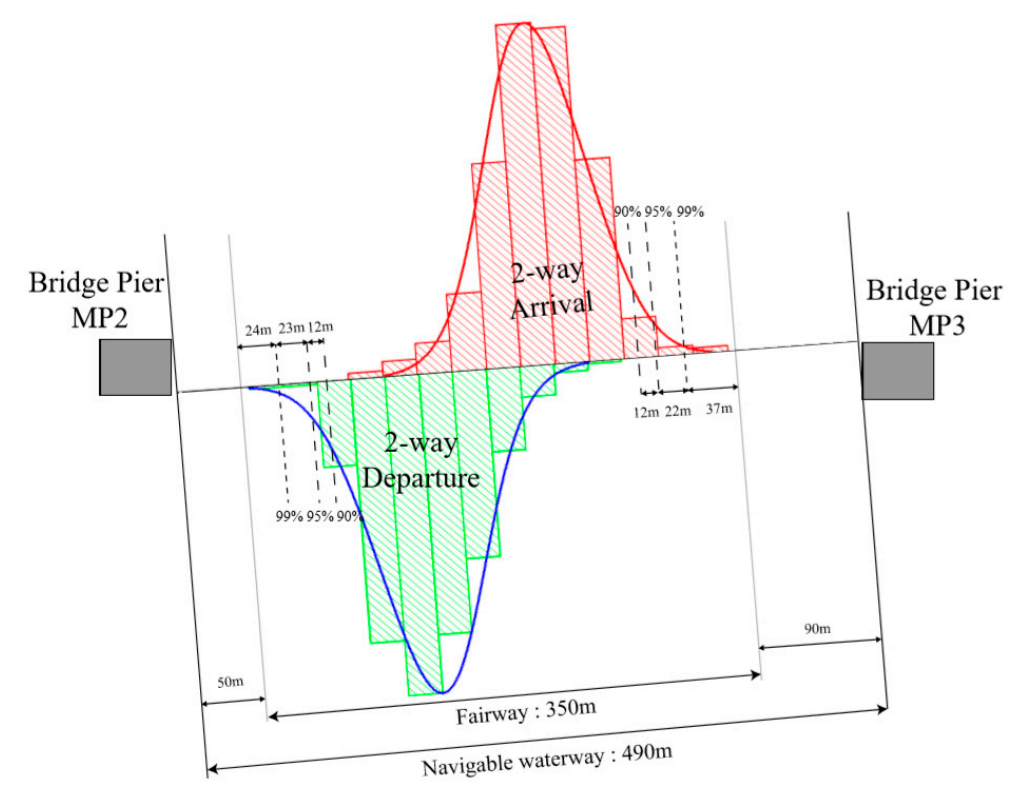

Figure 14. Traffic distribution for the Busan harbor bridge for 2-way traffic.

\subsection{Comparison of the Distance Difference between Bridge Pier and Ship}

Generally, to analyze the passage safety of routes and waters, an evaluation of the largest ship navigating through the target waters is necessary. In this study, the maximum ship breadth is utilized for the distance of 3.0 B [6] from the end of the fairway to the bridge pier proposed in a previous study, with the maximum ship breadth at the target bridges presented in Table 12. 
Table 12. Maximum breadth of bridge crossing waterway.

\begin{tabular}{cccc}
\hline \multirow{2}{*}{ Classification } & \multicolumn{2}{c}{ Incheon Bridge } & Busan Harbor Bridge \\
\cline { 2 - 4 } & 2-Way & 1-Way & 2-Way \\
\hline Max. breadth (m) & 37 & 60 & 38 \\
\hline
\end{tabular}

For 1-way traffic, the mean value is at the centerline of the waterway, while for 2-way traffic, it is on the right side of the centerline by 0.1 times the waterway, and standard deviation depends on the width of the waterway and traffic volume [35]. Therefore, at the Incheon bridge, the passage is relatively free because its navigable waterway is larger than at the Busan harbor bridge. Additionally, the 1-way traffic involves a lower arrival and departure distance difference than the 2-way traffic, since it exhibits the characteristics of navigating to the centerline of the waterway. Data from analyzing the absolute value differences by dividing the distances according to the confidence interval by the maximum ship's breadth are presented in Table 13.

Table 13. Data for distance divided by ship's maximum breadth for two bridges across waterways.

\begin{tabular}{|c|c|c|c|c|c|c|}
\hline \multirow{3}{*}{ Classification } & \multicolumn{4}{|c|}{ Incheon Bridge } & \multirow{2}{*}{\multicolumn{2}{|c|}{$\begin{array}{c}\text { Busan Harbor Bridge } \\
\text { 2-Way }\end{array}$}} \\
\hline & \multicolumn{2}{|c|}{ 2-Way } & \multicolumn{2}{|c|}{ 1-Way } & & \\
\hline & Arrival & Departure & Arrival & Departure & Arrival & Departure \\
\hline $80 \% \mathrm{CI}$ & $4.39 \mathrm{~B}$ & $4.46 \mathrm{~B}$ & $3.42 \mathrm{~B}$ & $3.00 \mathrm{~B}$ & $4.56 \mathrm{~B}$ & $3.24 \mathrm{~B}$ \\
\hline $85 \%$ CI & $3.93 \mathrm{~B}$ & $4.06 \mathrm{~B}$ & $3.23 \mathrm{~B}$ & $2.80 \mathrm{~B}$ & $4.41 \mathrm{~B}$ & $3.08 \mathrm{~B}$ \\
\hline $90 \% \mathrm{CI}$ & $3.34 \mathrm{~B}$ & $3.54 \mathrm{~B}$ & $2.98 \mathrm{~B}$ & $2.55 \mathrm{~B}$ & $4.21 \mathrm{~B}$ & $2.88 \mathrm{~B}$ \\
\hline $95 \% \mathrm{CI}$ & $2.43 \mathrm{~B}$ & $2.74 \mathrm{~B}$ & $2.59 \mathrm{~B}$ & $2.16 \mathrm{~B}$ & $3.91 \mathrm{~B}$ & $2.56 \mathrm{~B}$ \\
\hline $99 \% \mathrm{CI}$ & $0.68 \mathrm{~B}$ & $1.19 \mathrm{~B}$ & $1.85 \mathrm{~B}$ & $1.40 \mathrm{~B}$ & $3.33 \mathrm{~B}$ & $1.95 \mathrm{~B}$ \\
\hline
\end{tabular}

In Table 14, the difference in the arrivals and departures are presented, with the Incheon bridge showing a higher B (breadth) compared to arrival during the 2-way traffic, with differences between the arrival and departure increasing as the confidence interval increases. For the 1-way traffic, the arrival is higher than the departure and the difference is relatively constant, despite the higher confidence intervals. For the Busan harbor bridge, the arrival is 1.3 B higher than the departure (Figure 15).

Table 14. Data for the distance difference divided by the ship's maximum breadth for two bridges across waterways.

\begin{tabular}{cccc}
\hline \multirow{2}{*}{ Classification } & \multicolumn{3}{c}{ |Arrival-Departure| } \\
\cline { 2 - 4 } & \multicolumn{2}{c}{ Incheon Bridge } & Busan Harbor Bridge \\
\cline { 2 - 4 } & 2-Way & $\mathbf{1 - W a y}$ & 2-Way \\
\hline $\mathbf{8 0} \% \mathbf{C I}$ & $0.07 \mathrm{~B}$ & $0.42 \mathrm{~B}$ & $1.32 \mathrm{~B}$ \\
\hline $\mathbf{8 5 \%}$ CI & $0.13 \mathrm{~B}$ & $0.43 \mathrm{~B}$ & $1.33 \mathrm{~B}$ \\
\hline $\mathbf{9 0} \% \mathbf{C I}$ & $0.20 \mathrm{~B}$ & $0.43 \mathrm{~B}$ & $1.33 \mathrm{~B}$ \\
\hline $\mathbf{9 5 \%}$ CI & $0.31 \mathrm{~B}$ & $0.43 \mathrm{~B}$ & $1.35 \mathrm{~B}$ \\
\hline $\mathbf{9 9 \%} \mathrm{CI}$ & $0.51 \mathrm{~B}$ & $0.45 \mathrm{~B}$ & $1.38 \mathrm{~B}$ \\
\hline
\end{tabular}




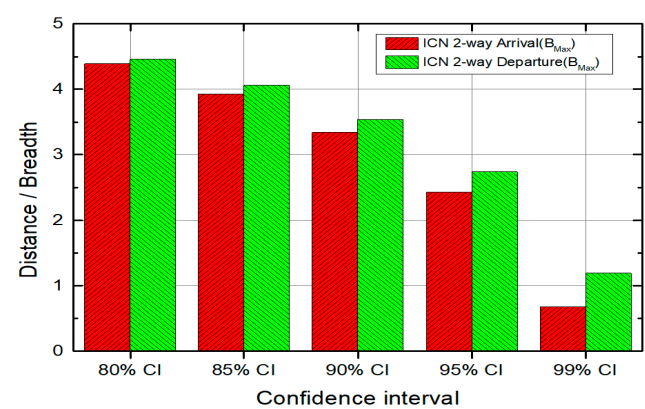

(a)

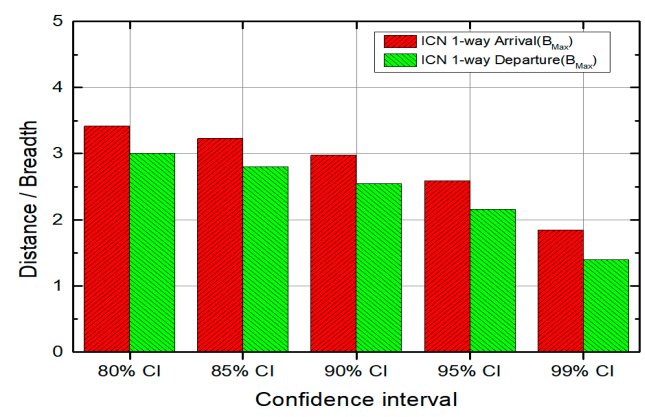

(c)

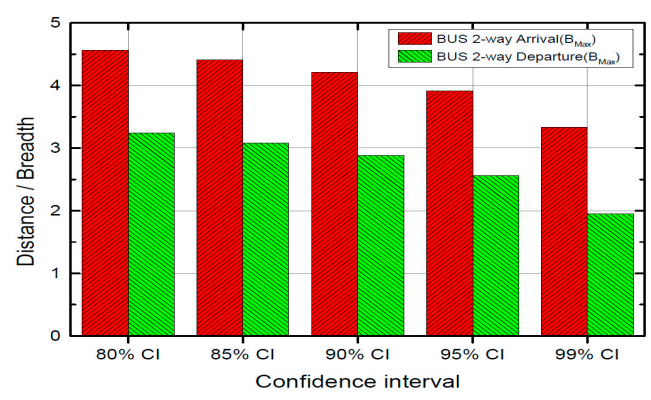

(e)

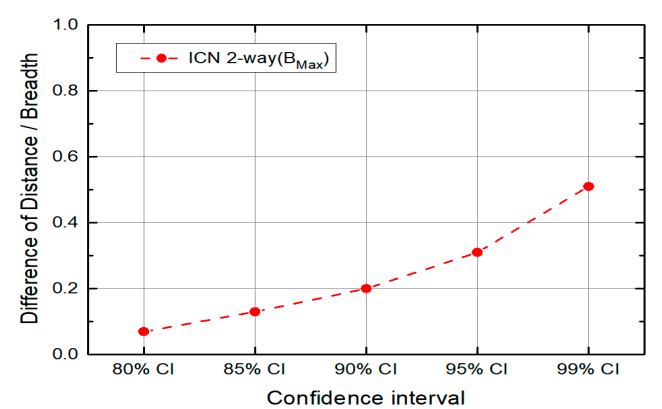

(b)

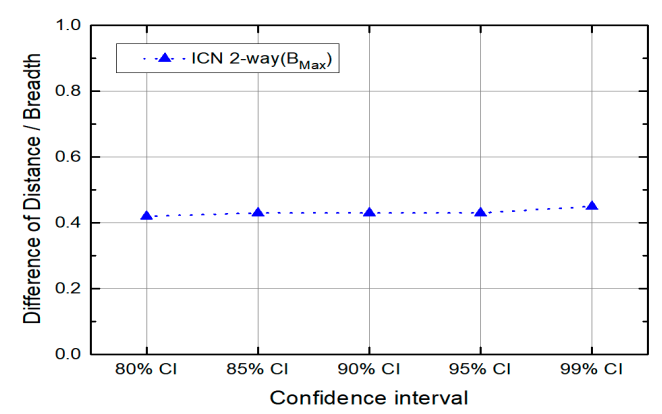

(d)

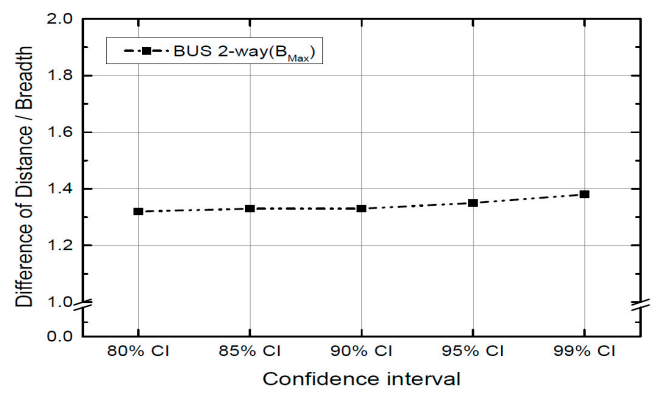

(f)

Figure 15. Distance difference divided by ship's maximum breadth at the Incheon bridge for $(\mathbf{a}, \mathbf{b})$ 2-way, (c,d) 1-way, and (e,f) Busan harbor bridge 2-way.

The variation in distances is depicted in Figure 16. For the 2-way traffic at the Incheon bridge, the variation is higher than for other cases as the confidence interval increases from $95 \%$ to $99 \%$. For the 1-way traffic, almost no variation exists, but it also increases significantly from $95 \%$ to $99 \%$ ranges. For the Busan harbor bridge, a little variation exists at $90 \%$, but most variations are from $95 \%$ to $99 \%$. From the analysis of the distances differences according to the confidence interval, it was inferred that the lower the difference between the arrival and departure, the more regular the passage pattern of the vessel from the traffic distribution (Table 15). 


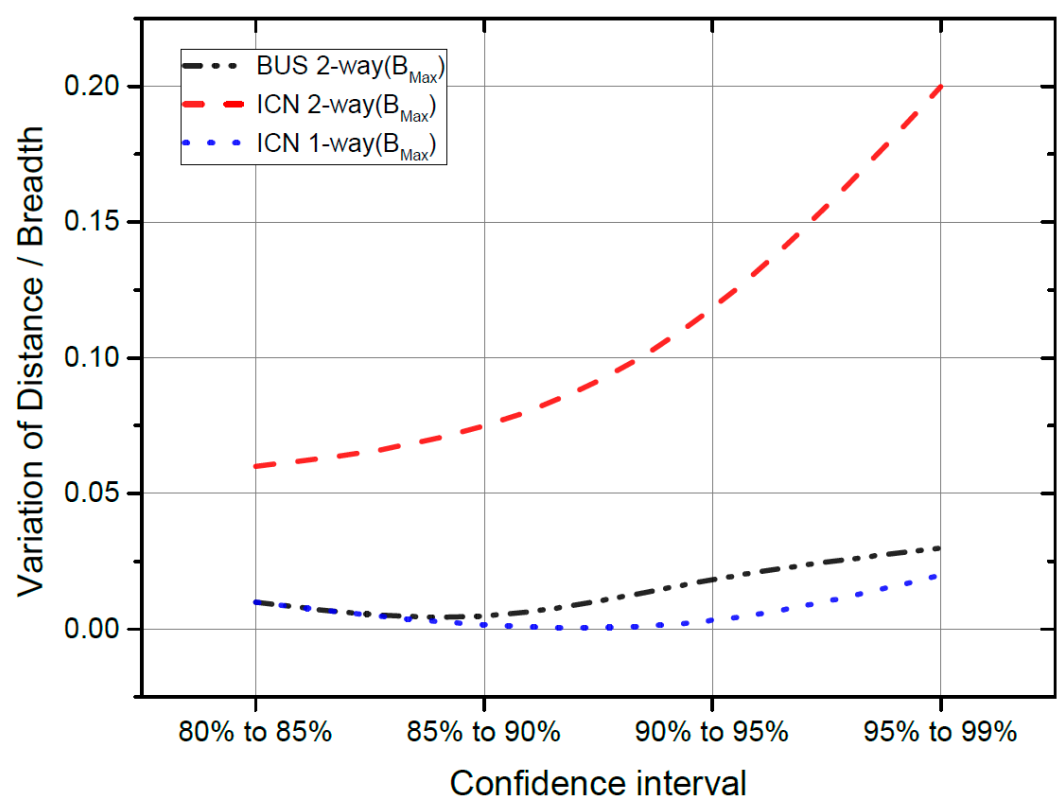

Figure 16. Variation of distances differences divided by the ship's maximum breadth.

Table 15. Data for variation of distances differences divided by the ship's maximum breadth.

\begin{tabular}{cccc}
\hline \multirow{2}{*}{ Classification } & \multicolumn{2}{c}{ Incheon Bridge } & Busan Harbor Bridge \\
\cline { 2 - 4 } & 2-Way & 1-Way & 2-Way \\
\hline $\mathbf{8 0 \%}$ to $\mathbf{8 5 \%}$ & $0.06 \mathrm{~B}$ & $0.01 \mathrm{~B}$ & $0.01 \mathrm{~B}$ \\
\hline $\mathbf{8 5 \%}$ to $\mathbf{9 0} \%$ & $0.07 \mathrm{~B}$ & $0.00 \mathrm{~B}$ & $0.00 \mathrm{~B}$ \\
\hline $\mathbf{9 0 \%}$ to $\mathbf{9 5} \%$ & $0.11 \mathrm{~B}$ & $0.00 \mathrm{~B}$ & $0.02 \mathrm{~B}$ \\
\hline $\mathbf{9 5 \%}$ to $\mathbf{9 9} \%$ & $0.20 \mathrm{~B}$ & $0.02 \mathrm{~B}$ & $0.03 \mathrm{~B}$ \\
\hline
\end{tabular}

\section{Discussion}

The analysis of maritime accidents between ships and bridges from the Korean Maritime Safety Tribunal (KMST) [42] for 2010-2019 is presented in Table 16, showing an average of 1.2 cases annually, with these attributed mostly to human error. Nevertheless, there is currently no distance standard between ships and bridges across waterways.

This study is basic research to propose a safety standard design for the main span and fairway layout of bridges across waterways to ensure the safety of port facilities and ships. The proposed safety standard design will provide quantitative safety standards to ship operators and ensure sufficient main span width for bridge design. In addition, in real-time active monitoring of Vessel Traffic Service (VTS), this will provide a safe range of passage for ship operators to prevent accidents in advance.

In this study, the traffic distributions at the Incheon bridge and the Busan harbor bridge, which are bridges across navigable waterways in Korea with different characteristics, were analyzed to obtain criteria for the safety distance for the bridge pier and ship. The AIS data were collected over a month in June 2019.

Normality tests according to the traffic distribution from the AIS data were performed using the Kolmogorov-Smirnov test, Normal Q-Q plot, skewness, and excess kurtosis. All results are confirmed to satisfy the normality test except for the 2-way traffic at the Incheon bridge. The 2-way traffic distribution at the Incheon bridge is, however, similar to a normal distribution, and samples collected through the sample size power calculation are sufficient to indicate statistical verification. We assumed that all traffic distributions for the target bridges follow normal distribution. The distance according to the $80-99 \%$ confidence interval, considering the wide bridge pier, ship impact protection size, and ship 
breadth is based on the Z-score. Results for confidence interval analysis of the traffic distributions are also based on Z-scores. For the Incheon bridge, all but one ship for the 2-way departure navigated within the $95 \%$ confidence intervals, and for the Busan harbor bridge, most of the ships, except for six arrivals and two ships of departure, are in the $95 \%$ range.

Table 16. Maritime accidents in Korea associated with bridges for 2010-2019.

\begin{tabular}{|c|c|c|c|}
\hline Accident Date & Bridge Name & Target Ship (G/T) & Cause \\
\hline 25 September 2010 & Geoje bridge & $\begin{array}{l}\text { Towing }(166 \mathrm{G} / \mathrm{T}) \\
\text { Barge }(1968 \mathrm{G} / \mathrm{T})\end{array}$ & Officer's carelessness \\
\hline 4 April 2011 & Geoje bridge & $\begin{array}{l}\text { Towing }(55 \mathrm{G} / \mathrm{T}) \\
\text { Barge }(932 \mathrm{G} / \mathrm{T})\end{array}$ & $\begin{array}{l}\text { Inadequate } \\
\text { passage plan }\end{array}$ \\
\hline 8 August 2011 & Jangja bridge & $\begin{array}{l}\text { Towing }(17 \mathrm{G} / \mathrm{T}) \\
\text { Barge }(530 \mathrm{G} / \mathrm{T})\end{array}$ & $\begin{array}{l}\text { Excessive navigation } \\
\text { during bad weather }\end{array}$ \\
\hline 25 August 2011 & Incheon bridge & Fishing $(10 \mathrm{G} / \mathrm{T})$ & Neglect of watch \\
\hline 24 August 2012 & Naro 2 bridge & Passenger $(228 \mathrm{G} / \mathrm{T})$ & Neglect of watch \\
\hline 29 August 2013 & Chunsa bridge & Cargo (1673G/T) & Drunken drowsiness \\
\hline 27 July 2013 & Shinan 1 bridge & Passenger $(307 \mathrm{G} / \mathrm{T})$ & $\begin{array}{c}\text { Excessive navigation } \\
\text { during restricted visibility }\end{array}$ \\
\hline 13 April 2016 & Jido bridge & Passenger $(228 \mathrm{G} / \mathrm{T})$ & $\begin{array}{c}\text { Speeding } \\
\text { during restricted visibility }\end{array}$ \\
\hline 27 September 2016 & Chunsa bridge & Tanker $(864 \mathrm{G} / \mathrm{T})$ & Neglect of watch \\
\hline 2 March 2018 & Geoje bridge & $\begin{array}{l}\text { Towing }(55 \mathrm{G} / \mathrm{T}) \\
\text { Barge }(932 \mathrm{G} / \mathrm{T})\end{array}$ & Excessive navigation \\
\hline 28 February 2019 & Gwangan bridge & Cargo (1673G/T) & Drunken negligence \\
\hline 14 October 2019 & Geoje bridge & $\begin{array}{l}\text { Towing }(55 \mathrm{G} / \mathrm{T}) \\
\text { Barge }(932 \mathrm{G} / \mathrm{T})\end{array}$ & Inadequate navigation \\
\hline
\end{tabular}

For 1-way traffic, the mean value is at the centerline of the waterway, whereas for 2-way traffic, it is on the right side of the centerline by 0.1 times the waterway; standard deviation depends on the width of the waterway and traffic volume. Therefore, at the Incheon bridge, the passage is relatively free because its navigable waterway is larger than that at the Busan harbor bridge. Additionally, the 1-way traffic involves a lower arrival and departure distance difference than the 2-way traffic as it exhibits the characteristics of navigating to the centerline of the waterway. Analysis of the variation of the resistance shift for arrival and departure shows the highest increase in the $95 \%$ to $99 \%$ ranges. Following analysis of the distance difference according to the confidence interval, it is inferred that the lower the difference between the arrival and departure, the more regular the passage pattern of the vessel from the traffic distribution.

According to the results of this study, the $95 \%$ confidence interval provides the optimal ship safety distance. A comparison of the $95 \%$ confidence interval distance divided by the maximum ship breadth with $3.0 \mathrm{~B}$ is presented in Table 17 . The differences between $-0.84 \mathrm{~B}$ to $+0.91 \mathrm{~B}$ are analyzed, especially for the Busan harbor bridge with over $3.0 \mathrm{~B}$ for arrival. This is because the fairway exhibits an asymmetrical arrangement (moved to the right). 
Table 17. Variation of distance difference divided by the ship maximum breadth.

\begin{tabular}{ccccccc}
\hline \multirow{2}{*}{ 95\% CI } & \multicolumn{4}{c}{ Incheon Bridge } & \multicolumn{2}{c}{ Busan Harbor Bridge } \\
\cline { 2 - 7 } & \multicolumn{2}{c}{ 2-Way } & \multicolumn{2}{c}{ 1-Way } & \multicolumn{2}{c}{ 2-Way } \\
\cline { 2 - 7 } & Arrival & Departure & Arrival & Departure & Arrival & Departure \\
\hline Target pier & E1 & W1 & E1 & W1 & MP3 & MP2 \\
\hline Distance (m) & 90 & 101 & 156 & 129 & 149 & 97 \\
\hline Distance/Breadth & $2.43 \mathrm{~B}$ & $2.74 \mathrm{~B}$ & $2.59 \mathrm{~B}$ & $2.16 \mathrm{~B}$ & $3.91 \mathrm{~B}$ & $2.56 \mathrm{~B}$ \\
\hline Difference from 3.0 B & $-0.57 \mathrm{~B}$ & $-0.26 \mathrm{~B}$ & $-0.41 \mathrm{~B}$ & $-0.84 \mathrm{~B}$ & $+0.91 \mathrm{~B}$ & $-0.44 \mathrm{~B}$ \\
\hline
\end{tabular}

The safety zone according to distribution corresponding to $95 \%$ of the confidence interval for 2-way traffic for the Incheon bridge proposed in this study is $529 \mathrm{~m}$, and it is within the $73.5 \%$ ranged based on the navigable waterway $(720 \mathrm{~m})$. The distance from the outer $95 \%$ confidence interval to the end of the fairway is set as the Precautionary zone. The Safety zone and Precautionary zone are set to the As Low As Reasonably Practicable Traffic zone. The Precautionary zone for 2-way traffic for the Incheon bridge is analyzed to be in the $13.4 \%$ range. The end of the fairway to the edge of the bridge pier is classified as the Risk zone, which represents $13.1 \%$ of the navigable waterway (Figure 17). Furthermore, for the Incheon bridge 1-way traffic, the data are over 14.7 times compared to the 2-way traffic, and so, the results were excluded from further consideration by adding additional sample data.

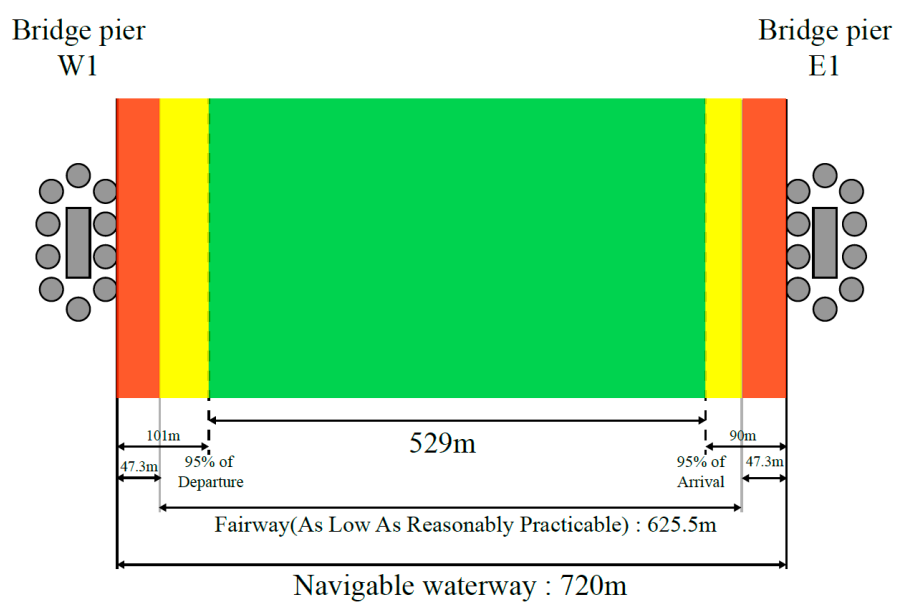

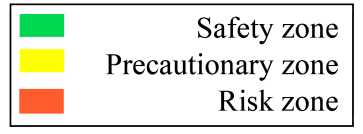

(b)

(a)

Figure 17. Ship safety distance for 2-way traffic situation at the (a) Incheon bridge and (b) legend.

For the Busan harbor bridge, the Safety zone according to traffic distribution corresponding to the $95 \%$ confidence interval is $244 \mathrm{~m}$, and it is within the $49.8 \%$ range based on the navigable waterway $(490 \mathrm{~m})$. The Precautionary zone is in the $21.6 \%$ range based on the navigable waterway, whereas the Risk zone is within the $28.6 \%$ range (Figure 18). 


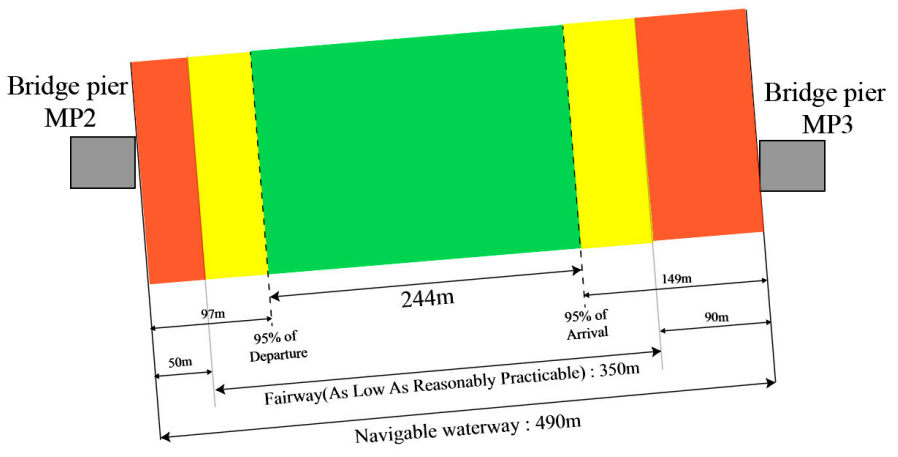

(b)

(a)

Figure 18. Ship safety distance for 2-way traffic at the (a) Busan harbor bridge and (b) legend.

\section{Conclusions}

For ship passage safety, a bridge across a waterway constitutes an accident risk factor. However, no safe distance standard between a bridge across a waterway and ships currently exists under the laws and regulations of Korea. In this study, according to traffic distribution, the Incheon and Busan harbor bridges in Korea were quantitatively assessed for a safe distance between the bridge piers edges and ships.

The traffic distributions of the Incheon and Busan harbor bridges were tested for normality. The distances were analyzed by confidence intervals according to Z-scores, considering the bridge pier width, ship impact protection size, and ship breadth. From comprehensive analysis of the distances according to confidence intervals, the $95 \%$ confidence interval emerged as the most suitable ship safety distance range. Therefore, the Safety zone was proposed as the $95 \%$ confidence interval range, whereas the Precautionary zone involved the range outside the $95 \%$ confidence interval to the fairway end, and the Risk zone comprised the distance between the fairway end and the bridge pier edge.

Through the quantitative safety distance based on port characteristics proposed to ship operators in this study, the accident rate due to a bridge across a navigable waterway can be reduced. Moreover, the design criteria for bridges across navigable waterways considering the safe distance and ships can be incorporated in the design based on the traffic characteristics of each port.

Future research, for the safety distance, will be to conduct a study that indicates sailing directions in various cases for the safety distance of the ship in consideration of the ship's maneuverability and weather conditions. It will be expected that the safety of port facilities and ships can be further strengthened.

Author Contributions: Conceptualization, I.-S.C. and W.-J.S.; methodology, W.-J.S.; validation, W.-J.S., J.-S.L., H.-T.L. and I.-S.C.; formal analysis, W.-J.S.; investigation, W.-J.S.; data curation, W.-J.S.; writing-original draft preparation, W.-J.S.; writing-review and editing, I.-S.C.; visualization, W.-J.S.; supervision, I.-S.C. All authors have read and agreed to the published version of the manuscript.

Funding: This research received no external funding.

Conflicts of Interest: The authors declare no conflict of interest.

\section{References}

1. Larson, O.D. Ship Collision with Bridge; International Association for Bridge and Structural Engineering: Zurich, Switzerland, 1993; pp. 1-6.

2. Gluver, H.; Olsen, D. Ship Collision Analysis: Proceedings of the International Symposium on Advances in the Ship Collision Analysis, Copenhagen, Denmark; CRC Press: Boca Raton, FL, USA, 1998; pp. 3-11. 
3. Park, Y.S.; Lee, Y.S.; Park, J.S.; Cho, I.S.; Lee, U. A proposal of Bridge Design Guideline by Analysis of Marine Accident Parameters occurred at Bridge Crossing Navigable Waterways. J. Navig. Port Res. 2008, 32, 743-750. [CrossRef]

4. Song, T.H.; Kim, Y.D. A Study on the Marine Traffic Safety Audit Scheme through Case Analysis. J. CDP 2018, 5, 193-201.

5. Lee, Y.S.; Park, Y.S.; Lee, U.; Jeong, C.H.; Park, J.S. A study on the Proper Location and Scale of Bridges Crossing Navigable Waterways Considering the Safety of Marine Traffic. J. Navig. Port Res. 2009, 33, $295-301$. [CrossRef]

6. Lee, Y.S.; Cho, I.S.; Song, C.U. A Study on the Analysis of Ship Handling Simulation about Domestic Sea Bridge over the Harbor. J. Navig. Port Res. 2008, 32, 321-326. [CrossRef]

7. Lee, Y.S.; Cho, I.S.; Park, J.S. Construction Processing Analysis of Domestic Bridges Crossing Navigable Waterways and Improvements. J. Korean Soc. Mar. Environ. Saf. 2009, 15, 119-125.

8. Lee, Y.S. A study on Adequacy of Audit Techniques and Advancement of Ship-Handling Simulation for Maritime Safety Audit. J. Korean Soc. Mar. Environ. Saf. 2011, 17, 391-398. [CrossRef]

9. Le Guyader, D.; Brosset, D.; Françoise, G. Exploitation de données AIS pour la cartographie du transport maritime. M@ppemonde 2012, 104, 1-15.

10. Maritime and Coastguard Agency (MCA). MGN 543(M+F) Safety of Navigation: Offshore Renewable Energy Installations (OREIs)-Guidance on UK Navigational Practice, Safety and Emergency Response; MCA: Southampton, UK, 2016; p. 18.

11. Cho, I.S.; Kim, I.C.; Lee, Y.S. The Introductory Concept of Maritime Safety Audit as a tool for Identifying Potential Hazards. J. Navig. Port Res. 2010, 34, 699-704. [CrossRef]

12. Tsuji, K. Methods of Survey for Marine Traffic. J. JIN 1996, 129, 8-18.

13. National Law Information Center. Traffic Rules for the Passage of Ships at Incheon and Kyeongin Port. Available online: https://www.law.go.kr/ (accessed on 14 February 2020).

14. Fujii, Y.; Makishima, T.; Hara, K. Marine Traffic Engineering; Kaibundo: Kawasaki, Japan, 1981; pp. 45, $119-129$.

15. Kim, D.Y.; Hong, T.H.; Jeong, J.S.; Lee, S.J. Building an Algorithm for Compensating AIS Error Data. J. Korean Inst. Intell. Syst. 2014, 24, 310-315. [CrossRef]

16. Olinsky, A.; Chen, S.; Harlow, L. The comparative efficacy of imputations methods for missing data in structural equation modeling. Eur. J. Oper. Res. 2003, 151, 53-79. [CrossRef]

17. Han, J.; Kamber, M.; Pei, J. Data Mining Concepts and Techniques, 3rd ed.; Elseiver: Amsterdam, The Netherlands, 2011; pp. 83-113.

18. Yoo, Y.; Kim, T.G. An Improved Ship Collision Risk Evaluation Method for Korea Maritime Safety Audit Considering Traffic Flow Characteristics. J. Mar. Sci. Eng. 2019, 7, 448. [CrossRef]

19. Port-MIS (Management Information System). Ship Entry and Exit Data of Incheon and Busan Port in Korea. Available online: https://new.portmis.go.kr/ (accessed on 2 February 2020).

20. KMST (Korea Maritime Safety Tribunal). 2015-2019 Annual Report of Marine Accident Statistics in Incheon and Busan Port. Available online: https://www.kmst.go.kr/ (accessed on 22 January 2020).

21. Mirović, M.; Miličević, M.; Obradović, I. Big data in the maritime industry. Nase More 2018, 65, 56-62. [CrossRef]

22. Lee, H.T. Analysis of Factors Influencing Berthing Velocity of Ship Using Machine Learning Prediction Algorithm. Master's Thesis, Korea Maritime and Ocean University, Busan, Korea, 2019.

23. Lee, J.S.; Son, W.J.; Lee, B.K.; Cho, I.S. Optimal Site Selection of Floating Offshore Wind Farm using Generic Algorithm. J. Korean Soc. Mar. Environ. Saf. 2019, 25, 658-665. [CrossRef]

24. Lee, B.K.; Cho, I.S.; Kim, D.H. A study on the Design of the Grid-Cell Assessment System for the Optimal Location of Offshore Wind Farms. J. Korean Soc. Mar. Environ. Saf. 2018, 24, 847-857. [CrossRef]

25. Son, W.J.; Lee, H.T.; Cho, I.S. A study on the Standard of Ship Safety Distance on Bridge Crossing Navigable Waterways based on Traffic Distribution. J. CDP 2020, 7, 29-37. [CrossRef]

26. Song, G.J. The Proposal for Positioning Accuracy Analysis and Stimulating Utilization of NDGPS. Master's Thesis, Chungnam National University, Daejeon, Korea, 2007.

27. Lee, D.J. Real-time monitoring of ship's dynamic behavior characteristics by AIS. J. Korean Soc. Fish. Ocean Technol. 2008, 44, 218-228. [CrossRef]

28. BPA (Busan Port Authority). Busan Northern Port Facility General. Available online: https://www.busanpa. com/kor/Contents.do?mCode=MN1578 (accessed on 30 January 2020). 
29. MOF (Ministry of Ocean and Fisheries). The Third National Port Basic Plan. Available online: http://www. mof.go.kr/article/view.do?menuKey=888\&boardKey=35\&articleKey=13469 (accessed on 21 March 2020).

30. Incheon Bridge Co, Ltd. Incheon Bridge Construction Note Sea Section. Available online: https://www. incheonbridge.com/eng/notice/resource (accessed on 30 January 2020).

31. Jang, S.J.; Sim, S.B.; Han, C.; Kim, M.B. Design and Construction of Underground Continuous Wall for Construction of Tower Foundation of North Busan Bridge. Korean Geotech. Soc. 2012, 11, 12-23.

32. Cohen, J. Statistical Power Analysis for the Behavioral Sciences; Lawrence Erlbaum Associates: Oxfordshire, UK, 1988; pp. 8-14.

33. Sheskin, D.J. Handbook of parametric and Nonparametric Statistical Procedures; CRC Press: Boca Raton, FL, USA, 2004; p. 54.

34. AASHTO (American Association of State Highway and Transportation Officials). Guide Specifications and Commentary for Vessel Collision Design of Highway Bridges, 2nd ed.; AASHTO: Washington, DC, USA, 2009.

35. Inoue, K. On the Separation of Traffic at Straight Waterway by Distribution Model of Ship. J. JIN 1977, 56, 103-115.

36. Kim, S.C.; Kwon, Y.B. A Review of Proximity Assessment Measurements According to Fairway Patterns and Ship Size. J. Korean Soc. Mar. Environ. Saf. 2017, 23, 783-790. [CrossRef]

37. Nguyen, X.T.; Park, Y.S.; Park, J.S.; Jeong, J.Y. Developing a program to Pre-process AIS data and applying to Vung Tau Waterway in Vietnam: Based on the IWRAP Mk2 program. J. Korean Soc. Mar. Environ. Saf. 2013, 19, 345-351. [CrossRef]

38. Triola, M.F. Elementary Statistics, 5th ed.; Addison-Wesley Pub: Boston, FL, USA, 1992; p. 730.

39. Kline, R.B. Principles and Practice of Structural Equation Modeling, 4th ed.; The Guilford Press: New-York City, NY, USA, 2015; pp. 74-77.

40. Fukunaga, K. Introduction to Statistical Pattern Recognition, 2nd ed.; Academic Press: Tokyo, Japan, 1990; pp. 75-84.

41. Henry, C.T. Testing for Normality; CRC Press: Boston, FL, USA, 2002; pp. 21-24.

42. KMST (Korea Maritime Safety Tribunal). Annual Report of Maritime Accident Written Verdict. Available online: https://www.kmst.go.kr/ (accessed on 22 January 2020).

(C) 2020 by the authors. Licensee MDPI, Basel, Switzerland. This article is an open access article distributed under the terms and conditions of the Creative Commons Attribution (CC BY) license (http://creativecommons.org/licenses/by/4.0/). 